\title{
Optimizing Design of High Strength Cement Matrix with Supplementary Cementitious Materials
}

\author{
Jun Zhang, Qing Wang, Zhenbo Wang \\ Department of Civil Engineering, Tsinghua University, Beijing, 100084
}

\begin{abstract}
In present paper, high strength cementitious matrix, special for high strength engineered cementitious composite (ECC) is designed using two kinds of cement, ordinary Portland cement (OPC) and calcium sulfoaluminate cement (SAC), two sand types (fine and coarse sand) and three supplementary cementitious materials
\end{abstract} (SCMs), silica fume (SF), slag (SG) and fly ash (FA). Optimized binder proportion with the addition of SF, SG and FA of high strength matrix are obtained through three series compressive and bending tests. The tensile performance of ECC utilizing above high strength matrix is investigated through uniaxial tensile tests. The test results show that through optimizing on the binder composition with SCMs, compressive and bending strength of the low water to binder ratio cement matrix is significantly increased. With a similar fluidity of the fresh mortar and under general curing condition, the compressive strength at 3, 7 and 28 days changes from 25.5, 43.0 and 59.8 MPa to 35.4, 61.9 and 85.6 MPa for SAC mortar with fine sand before and after binder optimization. For OPC fine sand mortar, the compressive strength at 3, 7 and 28 days changes from 45.0, 57.8 and 77.9 MPa to 62.0, 80.6 and 108.0 MPa. Similar trend is observed on the bending strength of those mortars as well. Based on the present study, the optimized binder composition with SF, SG and FA additions in weight are cement:SF:SG:FA=0.7:0.1:0.1:0.1. Using present optimized binder as cementing matrix, the primary tensile results on polyvinyl alcohol (PVA)-steel hybrid fiber reinforced composites show the tensile strength and strain can achieve 7.3 MPa, $0.6 \%$ and $8.1 \mathrm{MPa}, 0.5 \%$ respectively for SAC and OPC cementing system.

Key words: High-strength cementitious matrix; Supplementary cementitious materials; Engineered cementitious composite; PVA-steel Hybrid fibers 


\section{Introduction}

Concrete is a typical brittle material representing as first cracking in tension is accompanied by immediate localization of deformation followed by decreasing load. To overcome the brittle nature of concrete, a class of high performance fiber reinforced cementitious composite, called Engineered Cementitious Composites (ECC), has been developed in recent years [1]. This material has a unique property that after first cracking, tensile load-carrying capacity continues to grow, resulting in strain-hardening accompanied by multiple cracking. For each individual crack, the crack width first increases steadily up a certain level and then stabilizes at a constant value. Further increase in strain capacity is resulted from the formation of additional cracks until the cracking reaches a saturated state with crack spacing limited by the stress transfer capability of the fibers. After that, a single crack localizes and the load slowly drops with increased deformation. Typically, strain localization occurs at a tensile strain of $3-5 \%$, with crack spacing of $3-6 \mathrm{~mm}$ and crack width around $60 \mu \mathrm{m}$ [1]. Cracks of such a small width will have little effect on the water permeability of the material [2]. With slight degradation in transport properties under high deformation, the durability of the structure can be maintained.

However, in order to obtain this strain-hardening and multiple cracking behaviors, only a small amount of fine sand and relatively low strength of the matrix are allowed to be applied in order to control fracture toughness of matrix [3]. Generally, cement matrixes with compressive strength lower than $50 \mathrm{MPa}$ are used in ECC [3-6]. Even 
though the ability of crack width controlling of ECC is strong, a number of applications, such as permanent formwork for concrete structures, steel-concrete composite bridge decks [7-9], still wish the material has a relatively higher strength, meanwhile the material has adequate ductility. In these applications, material properties with low moisture transport coefficient, high freezing resistance and high permeability are required as well apart from ductility [9]. Therefore, high strength cement matrixes for a new generation of ECC focus on above applications are essentially needed to be developed. In addition, the cement content in ECC matrix is higher compared with conventional concrete, the possibility to use supplementary cementitious materials, such as silica fume, grounded granulated blast furnace slag and fly ash, in these high strength matrixes is of great interesting as well in the view of energy saving and sustainability of the materials.

In the present paper, high strength ECC matrix is designed using two kinds of cements, two types of silica sand and three kinds of supplementary cementitious materials (SCMs). The impacts of cement, sand and SCMs on compressive and bending strength of the matrix are experimentally evaluated. Optimized mix proportions with the addition of silica fume (SF), slag (SG) and fly ash (FA) of high strength cementitious matrix using two types of cement respectively are obtained. The tensile performance of ECCs utilizing above high strength matrixes is investigated through uniaxial tension tests. The results are discussed at the end of the paper. 


\section{Experimental Program}

The purpose of this test program is to investigate the effect of supplementary cementitious materials on compressive and bending strengths of high strength cement matrix, and finally to obtain the optimizing composition of high strength matrix binder. To achieve this target, three kinds of supplementary cementitious materials, silica fume (SF), grounded granulated blast furnace slag (SG) and fly ash (FA) were used in the experiments. To investigate the impact of sand size, two kinds of silica sands with particle size of 0.075 to $0.150 \mathrm{~mm}$ (fine sand) and 0.212 to $0.425 \mathrm{~mm}$ (coarse sand) were used respectively in the tests. To investigate the effect of cement type on the mechanical performance of the matrix, two cement types, portanland cement (OPC) and calcium sulfoaluminate cement (SAC) that has extra high early-age (in hours) strength [10], were used respectively as cementing materials. In order to obtain optimized proportions of the binder, three series tests, first is the addition of SF, second is the addition of SG, and third is the addition of FA, were carried out for each cement type. In each series, two kinds of sand described above were used respectively to form cement mortar.

In the first series of tests, the replacement of cement with SF in weight of the cement of $0 \%, 5 \%, 10 \%, 15 \%$ and $20 \%$ were used to form five cementing binders. Through compressive and bending tests on five cement mortars with constant sand to binder ratio of 0.833 and water to binder ratio of around 0.2 , the optimized amount of SF addition can then be obtained. After that, the second series of tests starts. In this series 
of tests, the optimized composition of cement and silica fume was used as the elementary mix proportion of the cementitious binder. The replacement of cement with SG in weight of the total binder of $0 \%, 10 \%, 20 \%, 30 \%$ and $40 \%$ was used to form another five cement binders. The same as used in the first series, through compressive and bending tests on the five cement mortars, the optimized amount of SL addition can then be obtained. Afterwards, third test series was carried out using the above optimized mixture with a fixed amount of SF and SG as the third elementary mix proportion of the binder. In the third series test, the replacement of cement with FA in weight of the total binder of $0 \%, 5 \%, 10 \%, 15 \%$ and $20 \%$ was used to form another five cement binders again. Through compressive and bending tests on the five cement mortars, the optimized amount of FA based on the previous optimized cementing system with additions of SF and SL can then be obtained. Thus, the final composition of cement, SF, SG and FA having the highest compressive and bending strengths of mortar is obtained. After that, tensile performance of ECC using the developed high strength matrix is investigated through uniaxial tensile tests.

\subsection{Materials}

The chemical compositions of the two cements (OPC and SAC) and the three SCMs (SF, SG, FA) used in tests are listed in Table 1. The particle size distribution of above five cementitious materials is shown in Fig. 1. As state previously, three series tests focus on the effect of SF, SG and FA respectively were carried out in the test program and the mix proportions of second and third series tests were based on the test results 
of the first and second series of tests respectively. Therefore, detailed mix proportions of each series will be given in the section of results and discussion in order. The fibers used to check the tensile performance of ECC with the developed high strength matrix include Polyvinyl alcohol fiber (PVA) supplied by kuraray company in Japan and steel fiber supplied by changhong company in China. The mechanical properties of the fibers are listed in Table 2. In the mix design of ECC, $2 \%$ volume fraction of the PVA fibers and $2 \%$ volume fractions of the steel fibers were applied.

\subsection{Specimens, curing and testing procedures}

Rectangular specimens with size of $40 \times 40 \times 160 \mathrm{~mm}$ was used to conduct the compressive and bending tests for each mixture at age of 3, 7 and 28 days after casting. The molds used to cast the specimens were made of steel. After removing from their molds, the specimens were stored in water at $20 \pm 2^{\circ} \mathrm{C}$ for curing until compressive and bending tests were carried out. For the uniaxial tensile test, rectangular coupon specimens with size of $100 \times 200 \times 20 \mathrm{~mm}$ were used. The same curing procedures were used for tensile specimens. The tensile specimens were tested in uniaxial tension with displacement control in a $250 \mathrm{kN}$ capacity MTS 810 material testing system with hydraulic wedge grips. Aluminum plates were epoxy glued onto the ends of the specimens prior to loading at least 6 hours to enhance the ends for gripping. The actuator displacement rate used for controlling the test was $0.0025 \mathrm{~mm}$ per second. The strain was measured by two extensometers mounted on the surface of the specimen. The measured gage length of extensometer was $50 \mathrm{~mm}$. 
142 The mixing procedure of the composite material consists of the following steps: (1) First,

143 the cementitious material and silica sand were mixed together for 2 minutes at low

144 speed. Then water with superplasticizer mixed in was gradually added, and mixing

145 was continued for 2 minutes which result in a uniform fluid matrix. Within this period,

146 the bottom of the mixing bowl should be scraped manually to ensure that no solid

147 materials stick to the bottom. After such scraping, the matrix was mixed at a higher

148 speed for 1 minute. If fibers were added, all fibers should be added after the above

149 preparation of matrix. The fibers were gradually spread into the mixer by hand as the

150 matrix was mixed at a slow speed. The fibers must be added slowly to ensure uniform

151 distribution with no fibers bundled together. (2) Casting and curing: The fresh mortar

152 without or with fibers was carefully cast into the mold in two layers. First about half

153 of the material was placed. Then the mix was vibrated for about 1-2 minutes to ensure

154 that the material was well compacted. Next, the second half of the mold was filled by

155 the composite in the same manner. After smoothing the surface, the specimens were

156 covered with a polyethylene sheet to prevent loss of moisture and stored for 24 hours

157 at room temperature prior to demolding.

159 3. Results and Discussion

$160 \quad 3.1$ Effect of SF on compressive and bending strengths of high strength mortar

161 To investigate the effect of silica fume on the compressive and bending strengths of

162 high strength matrix, five cementing binders with replacement of cement with silica 
fume in the total binder weight of $5 \%, 10 \%, 15 \%$ and $20 \%$ were made. A constant ratio of sand to binder in weight of 0.833 and water to cementitious ratio of approaching 0.2 was used, which depending on the workability of the matrix, to form mortars. Detailed mix proportions of mortars in this test series (I) are listed in Table 3 and Table 4 for SAC with the two sand type respectively and Table 5 and Table 6 for OPC with the two sands. The test results of the effect of silica fume addition on compressive and bending strength of the mortars are displayed in Fig.2 and Fig.3 for SAC mortars and Fig.4 and Fig.5 for OPC mortars.

From Table 3 and Table 4, we may note that the use of SF by replacing the same amount of cement in both fine and coarse sand mortar may lead increasing on the amount of superplasticizer as similar fluidity is maintained. This is understandable that the particle size of SF is less than that of cement particles. Meanwhile, for the similar fluidity, lower water to binder ratio can be obtained with OPC than that of SAC. This implies that the water requirement to achieve a given fluidity of the SAC mortar is larger than that of OPC mortar. In addition, as expected, coarse sand can lead to less water and superplasticizer to be used to obtain the same mortar fluidity.

From the test results shown in Figs. 2 to 5, we may find that the overall trend of compressive and bending strength of the mortars is first increasing then decreasing with increase of SF addition. Such tendency seems to be enhanced with the increase of age. A similar variation tendency is observed in both SAC and OPC mortars, 
whatever fine or coarse sand was used. According to present test results, the amount of SF addition is about $10 \%$ of the total binder weight to obtain the comparable highest compressive and bending strength of the mortar. The compressive strength at 3, 7 and 28 days of SAC matrix changes from 25.5, 43.0 and 59.8 MPa respectively to 28.9, 49.6 and 70.6 MPa for fine sand use. For coarse sand mortar, the compressive strength at 3, 7 and 28 days of SAC matrix changes from $39.5,55.6$ and $70.4 \mathrm{MPa}$ to 45.6, 67.7 and 79.2 MPa respectively. Accordingly, the bending strength at 3, 7 and 28 days of SAC matrix changes from 6.7, 9.3 and 9.5 MPa to 8.1, 10.5 and 11.1 MPa for fine sand use. For coarse sand mortar, the bending strength at 3, 7 and 28 days of SAC matrix changes from 8.9, 10.6 and 11.9 MPa to 11.3, 12.4 and 15.5MPa. For OPC matrix, the compressive strength at 3,7 and 28 days changes from 45.0, 57.8 and 77.9 MPa to 54.2, 70.1 and 92.2MPa for fine sand use. For coarse sand mortar, the compressive strength at 3,7 and 28 days of OPC matrix changes from 63.1, 72.2 and 92.4 MPa to 76.2, 84.7 and 104.2 MPa. The bending strength at 3, 7 and 28 days of OPC matrix changes from 8.1, 12.4 and 14.7 MPa to 9.6, 13.7 and 15.7 MPa for fine sand use. For coarse sand mortar, the bending strength at 3, 7 and 28 days of OPC matrix changes from 12.1, 14.6 and 19.4 MPa to $16.4,17.4$ and 21.0 MPa. Clearly, the effect of SF addition on strength of low water to binder ratio mortar is significant.

Based on above experimental results, the optimized binder composition with silica fume additions is obtained as cement:SF =0.9:0.1 in weight. The second series of tests (II) that will focus on the effect of slag addition on strength of SAC and OPC matrixes 
in which the above optimized binder composition will be used as the elementary mix proportion of the binder.

\subsection{Effect of SG on compressive and bending strength of high strength mortar}

211 Using $90 \%$ cement and $10 \%$ SF in weight as the elementary mix proportion of the binder, the replacement of cement with SG in total binder weight of $0 \%, 10 \%, 20 \%$, $30 \%$ and $40 \%$ were used to form five cementitious binders. The same as used in series approaching 0.2 was used, which depending on the workability of the matrix, to form mortars. The mix proportions of mortars in this test series (II) are listed in Table 3 and Table 4 for SAC with the two sand type respectively and Table 5 and table 6 for OPC Fig.8 and Fig.9 for OPC mortars. 
both SAC and OPC mortars, whatever fine or coarse sand was used. Based on the test results presented in test series II, the optimized amount of SG addition is about $10 \%$ of the total binder weight to obtain the highest compressive and bending strength of the mortar. Clearly, additional SG in the matrix containing SF already can further increase compressive and bending strength of the low water to binder ratio mortar. The function of SCMs on improvement of mechanical properties of low water to binder ratio mortar is significant. Based on above experimental results, the optimized binder composition with silica fume and slag additions is obtained as cement:SF:SG $=0.8: 0.1: 0.1$ in weight. The following third series tests (III) that will focus on the effect of fly ash addition on strength of SAC and OPC matrixes, in which the above optimized binder composition containing SF and SG will be used as the beginning mix proportion of the binder.

\subsection{Effect of FA on compressive and bending strength of high strength mortar}

To investigate the effect of fly ash addition on compressive and bending strengths of high strength mortar, mixture of $80 \%$ cement, $10 \%$ silica fume and $10 \%$ slag in weight was used as the elementary mix proportion of the cementitious binder. Again, a constant sand to binder ratio in weight of 0.833 and water to cementitious ratio of approaching 0.2 was used to for mortars in this test series (III). The replacement of cement with fly ash of the total binder weight of $0 \%, 5 \%, 10 \%, 15 \%$ and $20 \%$ was used to form another five cementitious binders including the reference. The mix proportions of mortars in test series III are listed in Table 3 and Table 4 for SAC with 
the two sand type respectively and Table 5 and table 6 for OPC with the two sands.

The test results of the effect of fly ash addition on compressive and bending strength of the mortars are displayed in Fig.10 and Fig.11 for SAC mortars and Fig.12 and Fig.13 for OPC mortars.

From Table 3 and Table 4, we may observe that the using FA to replace the same amount of cement in both fine and coarse sand mortars may lead decreasing on the requiring amount of superplasticizer as similar fluidity is maintained. This function is similar to that of SG addition. For similar fluidity, lower water to binder ratio can be obtained with OPC than that of SAC. These results indicate the characteristic of water absorption of SG and FA may be similar. From test results shown in Figs.10 to 11, it is interesting to see that with the increase of FA addition, both compressive and flexural strength are again first increasing then decreasing, even though $10 \%$ SF and $10 \%$ SG already are contained in the binder. This variation trend can be observed in both SAC and OPC system and in the fine and coarse sand system as well. According to the test results obtained in test series III, the optimized amount of additional FA addition is about $10 \%$ of the total binder weight to obtain the highest compressive and bending strength of the mortar. It should be pointed that addition of fly ash in normal strength concrete may lead to decrease the strength at early age, such as 3-day strength, and to increase the strength at later age, such as 1-year strength. However, this positive effect may depend on water to binder ratio. As very low water to binder ratio is used, for instance in the present work, the positive effect 
may take place early. Therefore, in the present study, 3-days strength is increased also as fly ash used, which looks different to conventional fly ash concrete.

The overall enhancing efficiency on compressive and bending strength of high strength SAC and OPC mortars, or called lower water to binder ratio mortar, by using silica fume, slag and fly ash in the matrix is graphically displayed in Figs.14 to 17, in which the highest average strength at 3, 7 and 28 days in each test series including the reference is presented. Obviously, through the optimizing procedure on the composition of cementing binder presented in this paper, compressive and bending strength of the low water to binder ratio matrix can significantly be increased in both SAC and OPC system. For example, with a similar fluidity of the fresh mortar, the compressive strength at 3, 7 and 28 days changes from 25.5, 43.0 and 59.8 $\mathrm{MPa}$ to 35.4, 61.9 and 85.6 MPa for SAC mortar with fine sand before and after binder optimization. The corresponding bending strength at 3, 7 and 28 days changes from 6.7, 9.3 and 9.5 MPa to 11.2, 14.2 and 14.9 MPa. For SAC coarse sand mortar, the compressive strength at 3, 7 and 28 days may change from 39.5, 55.6 and 70.4 MPa to 69.8, 92.2 and 97.7 MPa before and after binder optimization. The corresponding bending strength at 3, 7 and 28 days changes from 8.9, 10.6 and 11.9 $\mathrm{MPa}$ to 14.3, 16.7 and 17.9 MPa. For OPC fine sand mortar, the compressive strength at 3, 7 and 28 days changes from 45.0, 57.8 and 77.9 $\mathrm{MPa}$ to 62.0, 80.6 and 108.0 MPa. The corresponding bending strength at 3, 7 and 28 days may change from 8.1, 12.4 and 14.7 $\mathrm{MPa}$ to $10.9,15.2$ and $18.7 \mathrm{MPa}$. For OPC coarse sand mortar, the compressive 
strength at 3, 7 and 28 days changes from 63.1, 72.2 and 92.4 MPa to 78.5, 99.7 and 114.6 MPa. The corresponding bending strength at 3, 7 and 28 days may change from 12.1, 14.6 and 19.4 MPa to 16.8, 17.5 and 21.2 MPa. General range of strength increasing is about $20 \%$ to $70 \%$ of the reference. It is quite interesting that such significant strength increasing is based only on the optimization on composition of cementing binder with SF, SG and FA, those actually are industrial by-products and the cost is lower than cement in general. Based on present three series tests, the optimized binder composition with silica fume, slag and fly ash additions in weight is cement:SF:SG:FA=0.7:0.1:0.1:0.1.

From the particle size distribution curves displayed in Fig.1, we can find the particle size of silica fume, slag and fly ash is finer than cement particle. This nature may lead the filler action between cement particles may reduce the porosity of capillary pores in the matrix. Meanwhile, the introducing fine particles may increase the possible area for nucleation of C-S-H, which in turn increases in cement hydration degree as well. These two actions may help to increase of compressive and bending strength of the matrix. However, type of SCMs looks influencing the efficiency of strength improvement. This may indicate the possible reactions between cement hydration productions and the SCMs probably take place as well in early age cement hydration process.

3.4 Tensile performance of PVA-steel hybrid fiber reinforced cementitious 
Tensile performance of PVA and PVA-steel fiber reinforced cementitious composites using the developed high strength matrix is preliminary evaluated by uniaxial tension tests. It should be noted that as fiber added, a little more superplasticizer was used to make sure uniform distribution of fiber in the matrix. First, the effect of sand size on tensile behavior of the composites is investigated. Figs.18 to 21 displays the tensile stress-strain curves of the composites with fine and coarse sands respectively, in which 2\% PVA fiber was used. From the results, we may find that the strain-hardening performance, in terms of tensile strength and strain, is enhanced as fine sand was used. The average tensile strength and strain are $3.06 \mathrm{MPa}, 0.40 \%$ and 4.83 $\mathrm{MPa}, 0.39 \%$ respectively at 7 and 28 days for SAC in the case of fine sand used in the matrix. For coarse sand matrix, the tensile strength and strain becomes 2.64 $\mathrm{MPa}, 0.28 \%$ and $3.36 \mathrm{MPa}, 0.25 \%$ respectively at 7 and 28 days. For OPC, the corresponding values as fine sand was used are $4.14 \mathrm{MPa}, 0.34 \%$ and $5.04 \mathrm{MPa}$, 0.33\%. As coarse sand was used, the values are $3.89 \mathrm{MPa}, 0.26 \%$ and $4.47 \mathrm{MPa}$, $0.24 \%$ respectively. Obviously, the fine sand may enhance the tensile performance in

334 influence the fiber bridging stress across a crack in the composite, which in turn 335 influences the tensile behavior of the material. In the follow tests, the fine sand will be used only in the matrix to explore the possibility for further improvement of tensile performance of the composite. 
At present, most of the studies carried out on ECC have been focused on monofiber systems, such as polyvinyl alcohol poly (PVA) fiber or polyethylene (PE) fiber [1]. Meanwhile, a low strength matrix, compressive strength less than $50 \mathrm{MPa}$, is normally used in ECC [3, 4]. However, in a number of practical applications, such as permanent formwork for concrete structures, steel-concrete composite bridge decks [7-9], ECCs are wished to possess sufficient strain capacity, meanwhile adequate ultimate strength as well. Strength is a critical parameter that controls the penetration of chemical agent during service of the structures at the stage without cracking [11]. Strain capacity behaving as the formation of fine cracks is important for the long term durability of the structures at the stage that cracks may occur [12]. The balance optimization between strength and strain of the ECCs are definitely needed for better to meet the requirements of practical applications. Fiber reinforced cementitious composite containing with high-modulus monofiber normally exhibits high tensile strength but low strain capacity, such as steel and carbon fibers, whereas those containing relatively low modulus fibers, such as PE and PVA fibers, exhibit opposite behavior [8, 13-15]. Therefore, the tensile behavior of PVA-steel hybrid fiber reinforced ECC with developed high strength matrix is experimentally investigated in the following. Additional 2\% steel fiber in volume was added in the composite apart from 2\% PVA fiber. The uniaxial tensile test results are shown in Fig.22 and Fig.23 respectively for SAC and OPC system.

By comparing the results displayed in Fig.19 and Fig.22, Fig.21 and Fig.23 
respectively, it is obvious that the uniaxial tensile performance of the composites is significantly improved after steel fiber addition in both SAC and OPC system.

363 These improvements on tensile performance are displayed in the following aspects, increasing cracking and tensile strength, increasing cracking and ultimate tensile strain. Here, cracking strength and strain of the composite are defined as the tensile stress and strain at the end of the initial linear portion of the stress-strain curve [9]. For SAC cementing system, the cracking strength and strain at 28 days are 2.91 MPa, $0.010 \%$ and $5.93 \mathrm{MPa}, \mathbf{0 . 0 2 0 \%}$ respectively for the composites without and with $2 \%$ additional steel fiber addition. For OPC cementing system, the cracking strength and strain at 28 days are $2.81 \mathrm{MPa}$, $0.010 \%$ and $5.74 \mathrm{MPa}, \mathbf{0 . 0 1 6 \%}$ respectively for the composites without and with $2 \%$ additional steel fiber addition. Almost one time increment on cracking strength of the composite is observed. Meanwhile, the corresponding cracking strain of the composite is slightly increasing as well with the addition of steel fiber on tensile strength and strain of the composite is similar to the cracking respectively for the composites without and with $2 \%$ additional steel fiber addition. For OPC system, tensile strength and strain of the composites at 28 
without and with $2 \%$ additional steel fiber addition. Above enhancing law on cracking and tensile strength is based on high strength matrix. For low strength matrix, the efficiency of steel fiber will decrease due to the low fiber-matrix bond strength [12]. Therefore, we may conclude that the enhancing trend and/or rate of additional steel fiber on cracking and tensile strength of PVA fiber reinforced cement composite may vary with matrix strength or water to binder ratio of matrix. The above primary test results indicate that the addition of steel fiber in high strength ECCs can further increase the tensile strength and strain, which may satisfy the requirements of low water permeability and adequate ultimate tensile strain capacity on the composites.

\section{Conclusion}

In this paper, high strength cementitious matrix, special for high strength engineered cementitious composite (ECC) is designed using two kinds of cements, two sand types and three supplementary cementitious materials (SCM), silica fume (SF), slag (SG) and fly ash (FA). The impacts of cement, sand and SCMs on compressive and bending strength of the matrix are first experimentally evaluated. Optimized mix proportion with the addition of SF, SG and FA of high strength cementitious matrix for the two kinds of cement respectively is obtained. The preliminary tensile performance of ECCs utilizing above high strength matrix is investigated through uniaxial tensile tests. 
The test results shown that through the optimizing procedure on the composition of cementing binder with SCMs, including SF, SG and FA, compressive and bending strength of the low water to binder ratio cementing matrix is significantly increased with ordinary Portland cement (OPC) and calcium sulfoaluminate cement (SAC) respectively. With a similar fluidity of the fresh mortar, the compressive strength at 3 , 7 and 28 days changes from 25.5, 43.0 and 59.8 MPa to 35.4, 61.9 and 85.6 MPa for SAC mortar with fine sand before and after binder optimization. For SAC coarse sand mortar, the compressive strength at 3, 7 and 28 days changes from 39.5, 55.6 and 70.4 MPa to 69.8, 92.1 and 97.7 MPa. For OPC fine sand mortar, the compressive strength at 3, 7 and 28 days changes from 45.0, 57.8 and 77.9 MPa to 62.0, 80.6 and 108.0 MPa. For OPC coarse sand mortar, the compressive strength at 3, 7 and 28 days changes from 63.1, 72.2 and 92.4 MPa to 78.5, 99.1 and 114.6 MPa. Similar results are obtained on bending strength of the mortars. General range of strength increasing is about $20 \%$ to $70 \%$ of the reference. Based on present three series tests, the optimized binder composition with silica fume, slag and fly ash additions in weight is cement:SF:SG:FA=0.7:0.1:0.1:0.1. Utilizing present optimized binder as cementing matrix, the primary tensile test results on PVA-steel hybrid fiber reinforced composites show that the uniaxial tensile strength and strain can achieve 7.3 $\mathrm{MPa}$, $0.6 \%$ and $8.1 \mathrm{MPa}, 0.5 \%$ respectively for SAC and OPC cementing system.

\section{Acknowledgements}

Support from National Science Foundation of China (No.51278278) to Tsinghua 
University are gratefully acknowledged.

\section{References}

430 [1] Li, V.C., Advances in ECC Research, ACI Special Publication on Concrete: Material Science to Applications, SP 206-23, 2002, p. 373-400.

[2] Li, V.C., From Micromechanics to structural engineering--the design of cementitious composites for civil engineering applications. JSCE J. of Struc. Mechanics and Earthquake Engineering, 1993;10(2):37-48.

[3] Li, V.C., Mishra, D.K., and Wu, H.C., Matrix design for pseudo strain-hardening fiber reinforced cementitious composites. Materials and Structures, 1995; 28(183): 586-595.

[4] Zhang, J. and Leng B., The transition from macro-multiple cracking to micro-multiple cracking in cementitious composites, Tsinghua Science and Technology, 2008; 13(5):669-673.

[5] Zhang, J., Li, V.C., Andrzej S.N, Wang S., Introducing Ductile Strip for Durability Enhancement of Concrete Slabs. Journal of Materials in Civil Engineering, 2002;14(3):253-261.

[6] Zhang, J. Gong, C., Zhang, M. and Guo, Z., Engineered Cementitious Composite with Characteristic of Low Drying Shrinkage, Cement and Concrete Research, 2009; 39(4): 303-312.

[7] Shao, X., Yi, D., Huang, Z., Zhao, H., Chen, B., and Liu, M., Basic Performance of the Composite Deck System Composed of Orthotropic Steel Deck and Ultra thin RPC Layer, Journal of Bridge Engineering, 2013; 18(5): 417-428. 
[8] Zhang, J., Wang, Z., Ju, X. and Shi, Z., Simulation of Flexural Performance of Layered ECC-Concrete Composite Beam with Fracture Mechanics Model. Engineering Fracture Mechanics, 2014; 131:419-438.

[9] Wang Z., Zhang, J., Wang J. and Shi, Z., Tensile Performance of Polyvinyl Alcohol-Steel Hybrid Fiber Reinforced Cementitious Composite with Impact of Water to Binder Ratio. Journal of Composites, 2015; 49(18):2169-2186.

[10] Zhang, J., Luosun Y., Wang J. and Han Y.,. Shrinkage of High Strength Calcium Sulfoaluminate Cement Concrete with Impact of Pre-soaked Lightweight Aggregate Internal Curing. Magazine of Concrete Research, 2015; 72(22): 1204-1213.

[11] Neville, A.M. Properties of Concrete, $3^{\text {rd }}$ Edition, Pitman Publishing Limited, 1981.

[12] Wang K.J., Jansen, D.C. Shah, S.P. and Karr, A.F. Permeability study of cracked concrete. Cement and Concrete Research, 1997; 27(3):381-393.

[13] Maalej, M., Quek, S., and Zhang, J. Behavior of Hybrid-Fiber Engineered Cementitious Composites Subjected to Dynamic Tensile Loading and Projectile Impact. Journal of Materials in Civil Engineering, 2005; 17(2):143-152.

[14] Zhang, J., Maalej, M., and Quek, S. Performance of Hybrid-Fiber ECC Blast/Shelter Panels Subjected to Drop Weight Impact. Journal of Materials in Civil Engineering, 2007; 19(10):855-863.

[15] Li, V. C. Stang, H. and Krenchel, H. Micromechanics of crack bridging in fibre-reinforced concrete. Materials and Structures, 1993; 26(8):486-494. 
Table 1. Chemical composition of the cementitious materials used in tests (wt $\%$ )

\begin{tabular}{cccccccccc}
\hline $\mathrm{No}$ & $\mathrm{SiO}_{2}$ & $\mathrm{CaO}$ & $\mathrm{Al}_{2} \mathrm{O}_{3}$ & $\mathrm{Fe}_{2} \mathrm{O}_{3}$ & $\mathrm{MgO}$ & $\mathrm{K}_{2} \mathrm{O}$ & $\mathrm{Na}_{2} \mathrm{O}$ & $\mathrm{SO}_{3}$ & $\mathrm{LOI}$ \\
\hline $\mathrm{SAC}$ & 6.19 & 42.9 & 24.16 & 1.04 & 1.96 & 0.48 & 0.08 & 12.91 & 8.91 \\
OPC & 23.67 & 59.98 & 7.21 & 3.07 & 2.07 & 0.62 & 0.17 & 2.14 & 1.01 \\
Silica fume (SF) & 90.56 & 0.81 & 0.41 & 0.52 & 0.95 & 1.59 & 0.63 & - & 3.72 \\
Fly ash (FA) & 47.02 & 5.08 & 35.06 & 3.88 & 1.36 & 1.30 & 1.18 & 0.89 & 1.85 \\
Slag (SG) & 38.83 & 38.70 & 12.92 & 1.46 & 4.63 & 0.37 & 0.28 & 0.60 & 0.06 \\
\hline
\end{tabular}

474

475

476

477

Table 2. Properties of PVA and steel fibers

\begin{tabular}{lccccc}
\hline & $\begin{array}{c}\text { Density } \\
\left(\mathrm{g} / \mathrm{cm}^{3}\right)\end{array}$ & $\begin{array}{c}\text { Tensile strength } \\
(\mathrm{MPa})\end{array}$ & $\begin{array}{c}\mathrm{E} \\
(\mathrm{GPa})\end{array}$ & $\begin{array}{c}\text { Diameter } \\
(\mathrm{mm})\end{array}$ & $\begin{array}{c}\text { Length } \\
(\mathrm{mm})\end{array}$ \\
\hline PVA fiber & 1.2 & 1620 & 42.8 & 0.039 & 12 \\
\hline Steel fiber & 7.8 & 2750 & 210 & 0.200 & 13 \\
\hline
\end{tabular}

Table 3. Mix Proportions of SAC-fine sand mortar

\begin{tabular}{ccccc}
\hline $\begin{array}{c}\text { Test Series } \\
\text { SAC }\end{array}$ & Cementitious Materials & Sand & Water & $\begin{array}{c}\text { Superplasticizer } \\
(\%)\end{array}$ \\
\hline & Total(Cement:SF:SG:FA) & $0.075-0.150 \mathrm{~mm}$ & & 0.200 \\
I(SF) & $1(1.00: 0.00: 0: 00: 0.00)$ & & 0.203 & 2.29 \\
& $1(0.90: 0.10: 0: 00: 0.00)$ & 0.833 & 0.204 & 2.31 \\
& $1(0.85: 0.15: 0: 00: 0.00)$ & & 0.207 & 2.43 \\
& $1(0.80: 0.20: 0: 00: 0.00)$ & & 0.209 & 2.54 \\
\hline \multirow{2}{*}{ II(SG) } & $1(0.90: 0.10: 0.00: 0.00)$ & & 0.204 & 2.31 \\
& $1(0.80: 0.10: 0.10: 0.00)$ & & 0.202 & 2.24 \\
& $1(0.70: 0.10: 0.20: 0.00)$ & 0.833 & 0.201 & 2.18 \\
& $1(0.60: 0.10: 0.30: 0.00)$ & & 0.199 & 2.11 \\
& $1(0.50: 0.10: 0.40: 0.00)$ & & 0.198 & 2.05 \\
\hline \multirow{2}{*}{ III(FA) } & $1(0.80: 0.10: 0.10: 0.00)$ & & 0.202 & 2.24 \\
& $1(0.75: 0.10: 0.10: 0.05)$ & & 0.198 & 2.08 \\
& $1(0.70: 0.10: 0.10: 0.10)$ & 0.833 & 0.197 & 2.00 \\
& $1(0.65: 0.10: 0.10: 0.15)$ & & 0.196 & 1.98 \\
& $1(0.60: 0.10: 0.10: 0.20)$ & & 0.195 & 1.92 \\
\hline
\end{tabular}

478

Table 4. Mix Proportions of SAC-coarse sand mortar

\begin{tabular}{ccccc}
\hline $\begin{array}{c}\text { Test Series } \\
\text { SAC }\end{array}$ & $\begin{array}{c}\text { Cementitious Materials } \\
\text { Total(Cement:SF:SG:FA) }\end{array}$ & $\begin{array}{c}\text { Sand } \\
0.212-0.425 \mathrm{~mm}\end{array}$ & Water & $\begin{array}{c}\text { Superplasticizer } \\
(\%)\end{array}$ \\
\hline \multirow{2}{*}{ I(SF) } & $1(1.00: 0.00: 0: 00: 0.00)$ & & 0.180 & 1.30 \\
& $1(0.95: 0.05: 0: 00: 0.00)$ & & 0.182 & 1.36 \\
& $1(0.90: 0.10: 0: 00: 0.00)$ & 0.833 & 0.183 & 1.43 \\
& $1(0.85: 0.15: 0: 00: 0.00)$ & & 0.185 & 1.49 \\
II(SG) & $1(0.80: 0.20: 0: 00: 0.00)$ & & 0.188 & 1.62 \\
\hline \multirow{2}{*}{$1(0.90: 0.10: 0.00: 0.00)$} & \multirow{2}{*}{0.833} & 0.183 & 1.43 \\
& $1(0.80: 0.10: 0.10: 0.00)$ & & 0.177 & 1.17
\end{tabular}




\begin{tabular}{|c|c|c|c|c|}
\hline & 1(0.70:0.10:0.20:0.00) & & 0.175 & 1.07 \\
\hline & 1(0.60:0.10:0.30:0.00) & & 0.175 & 1.07 \\
\hline & 1(0.50:0.10:0.40:0.00) & & 0.175 & 1.07 \\
\hline \multirow{5}{*}{ III(FA) } & 1(0.80:0.10:0.10:0.00) & \multirow{5}{*}{0.833} & 0.177 & 1.17 \\
\hline & 1(0.75:0.10:0.10:0.05) & & 0.171 & 0.88 \\
\hline & 1(0.70:0.10:0.10:0.10) & & 0.171 & 0.88 \\
\hline & 1(0.65:0.10:0.10:0.15) & & 0.169 & 0.83 \\
\hline & $1(0.60: 0.10: 0.10: 0.20)$ & & 0.168 & 0.78 \\
\hline
\end{tabular}

480

481

Table 5. Mix Proportions of OPC-fine sand mortar

\begin{tabular}{ccccc}
\hline $\begin{array}{c}\text { Test Series } \\
\text { OPC }\end{array}$ & $\begin{array}{c}\text { Cementitious Materials } \\
\text { Total(Cement:SF:SG:FA) }\end{array}$ & $\begin{array}{c}\text { Sand } \\
0.075-0.150 \mathrm{~mm}\end{array}$ & Water & $\begin{array}{c}\text { Superplasticizer } \\
(\%)\end{array}$ \\
\hline \multirow{3}{*}{ I(SF) } & $1(1.00: 0.00: 0: 00: 0.00)$ & & 0.192 & 1.79 \\
& $1(0.95: 0.05: 0: 00: 0.00)$ & & 0.194 & 1.89 \\
& $1(0.90: 0.10: 0: 00: 0.00)$ & 0.833 & 0.195 & 1.95 \\
& $1(0.85: 0.15: 0: 00: 0.00)$ & & 0.199 & 2.11 \\
& $1(0.80: 0.20: 0: 00: 0.00)$ & & 0.203 & 2.28 \\
\hline \multirow{3}{*}{ II(SG) } & $1(0.90: 0.10: 0.00: 0.00)$ & & 0.195 & 1.95 \\
& $1(0.80: 0.10: 0.10: 0.00)$ & & 0.181 & 1.32 \\
& $1(0.70: 0.10: 0.20: 0.00)$ & 0.833 & 0.180 & 1.30 \\
& $1(0.60: 0.10: 0.30: 0.00)$ & & 0.177 & 1.17 \\
III(FA) & $1(0.50: 0.10: 0.40: 0.00)$ & & 0.177 & 1.17 \\
\hline & $1(0.80: 0.10: 0.10: 0.00)$ & & 0.181 & 1.32 \\
& $1(0.75: 0.10: 0.10: 0.05)$ & & 0.178 & 1.20 \\
& $1(0.70: 0.10: 0.10: 0.10)$ & 0.833 & 0.177 & 1.14 \\
& $1(0.65: 0.10: 0.10: 0.15)$ & & 0.175 & 1.07 \\
\hline
\end{tabular}

482

Table 6. Mix Proportions of OPC-coarse sand mortar

\begin{tabular}{ccccc}
\hline $\begin{array}{c}\text { Test Series } \\
\text { OPC }\end{array}$ & $\begin{array}{c}\text { Cementitious Materials } \\
\text { Total(Cement:SF:SG:FA) }\end{array}$ & $\begin{array}{c}\text { Sand } \\
0.212-0.425 \mathrm{~mm}\end{array}$ & Water & $\begin{array}{c}\text { Superplasticizer } \\
(\%)\end{array}$ \\
\hline \multirow{3}{*}{ I(SF) } & $1(1.00: 0.00: 0: 00: 0.00)$ & & 0.169 & 0.80 \\
& $1(0.95: 0.05: 0: 00: 0.00)$ & & 0.170 & 0.84 \\
& $1(0.90: 0.10: 0: 00: 0.00)$ & 0.833 & 0.170 & 0.88 \\
& $1(0.85: 0.15: 0: 00: 0.00)$ & & 0.173 & 0.98 \\
& $1(0.80: 0.20: 0: 00: 0.00)$ & & 0.175 & 1.06 \\
\hline \multirow{3}{*}{ II(SG) } & $1(0.90: 0.10: 0.00: 0.00)$ & & 0.171 & 0.88 \\
& $1(0.80: 0.10: 0.10: 0.00)$ & & 0.169 & 0.81 \\
& $1(0.70: 0.10: 0.20: 0.00)$ & 0.833 & 0.167 & 0.73 \\
& $1(0.60: 0.10: 0.30: 0.00)$ & & 0.165 & 0.65 \\
III(FA) & $1(0.50: 0.10: 0.40: 0.00)$ & & 0.164 & 0.62 \\
\hline \multirow{2}{*}{} & $1(0.80: 0.10: 0.10: 0.00)$ & \multirow{2}{*}{0.833} & 0.169 & 0.81 \\
& $1(0.75: 0.10: 0.10: 0.05)$ & & 0.167 & 0.73 \\
\hline
\end{tabular}




\begin{tabular}{ccc}
\hline $1(0.70: 0.10: 0.10: 0.10)$ & 0.166 & 0.70 \\
$1(0.65: 0.10: 0.10: 0.15)$ & 0.164 & 0.62 \\
$1(0.60: 0.10: 0.10: 0.20)$ & 0.163 & 0.55 \\
\hline
\end{tabular}

484

485

486

487

488

489

490

491

492

493

494

495

496

497

498

499

500

501

502

503

504

505

506

507

508

509

510

511

512

513

514

515

516

517

518

519

520

521

522

523

524

Table and Figure Captions

Table 1. Chemical composition of the cementitious materials used in tests (wt\%)

Table 2. Properties of PVA and steel fibers

Table 3. Mix Proportions of SAC-fine sand mortar

Table 4. Mix Proportions of SAC-coarse sand mortar

Table 5. Mix Proportions of OPC-fine sand mortar

Table 6. Mix Proportions of OPC-coarse sand mortar

Fig.1 Particle size distribution of the five fine cementitious materials

Fig.2 Effect of silica fume addition on strength of the SAC-fine sand mortar, (a) compressive strength, (b) bending strength

Fig.3 Effect of silica fume addition on strength of the SAC-coarse sand mortar, (a) compressive strength, (b) bending strength

Fig.4 Effect of silica fume addition on strength of OPC-fine sand mortar, (a) compressive strength, (b) bending strength

Fig.5 Effect of silica fume addition on strength of OPC-coarse sand mortar, (a) compressive strength, (b) bending strength

Fig.6 Effect of slag addition on strength of the SAC mortar with fine sand, (a) compressive strength, (b) bending strength

Fig.7 Effect of slag addition on strength of SAC-coarse sand mortar, (a) compressive strength, (b) bending strength

Fig.8 Effect of slag addition on strength of the OPC-fine sand mortar, (a) compressive strength, (b) bending strength

Fig.9 Effect of slag addition on strength of OPC-coarse sand mortar, (a) compressive strength, (b) bending strength

Fig.10 Effect of fly ash addition on strength of the SAC-fine sand mortar, (a) compressive strength, (b) bending strength

Fig.11 Effect of fly ash addition on strength of the SAC-coarse sand mortar, (a) compressive strength, (b) bending strength

Fig.12 Effect of fly ash addition on strength of the OPC-fine sand mortar, (a) compressive strength, (b) bending strength

Fig.13 Effect of fly ash addition on strength of the OPC-coarse sand mortar, (a) compressive strength, (b) bending strength

Fig.14 Effect of optimized SCM addition on compressive and bending strength of the SAC-fine sand mortar, (a) compressive strength, (b) bending strength

Fig.15 Effect of optimized SCM addition on compressive and bending strength of the SAC-coarse sand mortar, (a) compressive strength, (b) bending strength

Fig.16 Effect of optimized SCM addition on compressive and bending strength of the OPC-fine sand mortar, (a) compressive strength, (b) bending strength

Fig.17 Effect of optimized SCM addition on compressive and bending strength of the OPC-coarse sand mortar, (a) compressive strength, (b) bending strength 
525 Fig.18 Tensile stress-strain curves of SAC-coarse sand matrix reinforced with 2\% PVA fiber, (a) 7 526 days, (b) 28 days

527 Fig.19 Tensile stress-strain curves of SAC-fine sand matrix reinforced with 2\% PVA fiber, (a) 7 528 days, (b) 28 days

529 Fig.20 Tensile stress-strain curves of OPC-coarse sand matrix reinforced with 2\% PVA fiber, (a) 7 530 days, (b) 28 days

531 Fig.21 Tensile stress-strain curves of OPC-fine sand matrix reinforced with 2\% PVA fiber, (a) 7 532 days, (b) 28 days

533 Fig.22Tensile stress-strain curves of SAC-fine sand matrix reinforced with 2\% PVA fiber and 2\% 534 steel fiber, (a) 7 days, (b) 28 days

535 Fig.23 Tensile stress-strain curves of SAC-fine sand matrix reinforced with 2\% PVA fiber and 2\% 536 steel fiber, (a) 7 days, (b) 28 days 


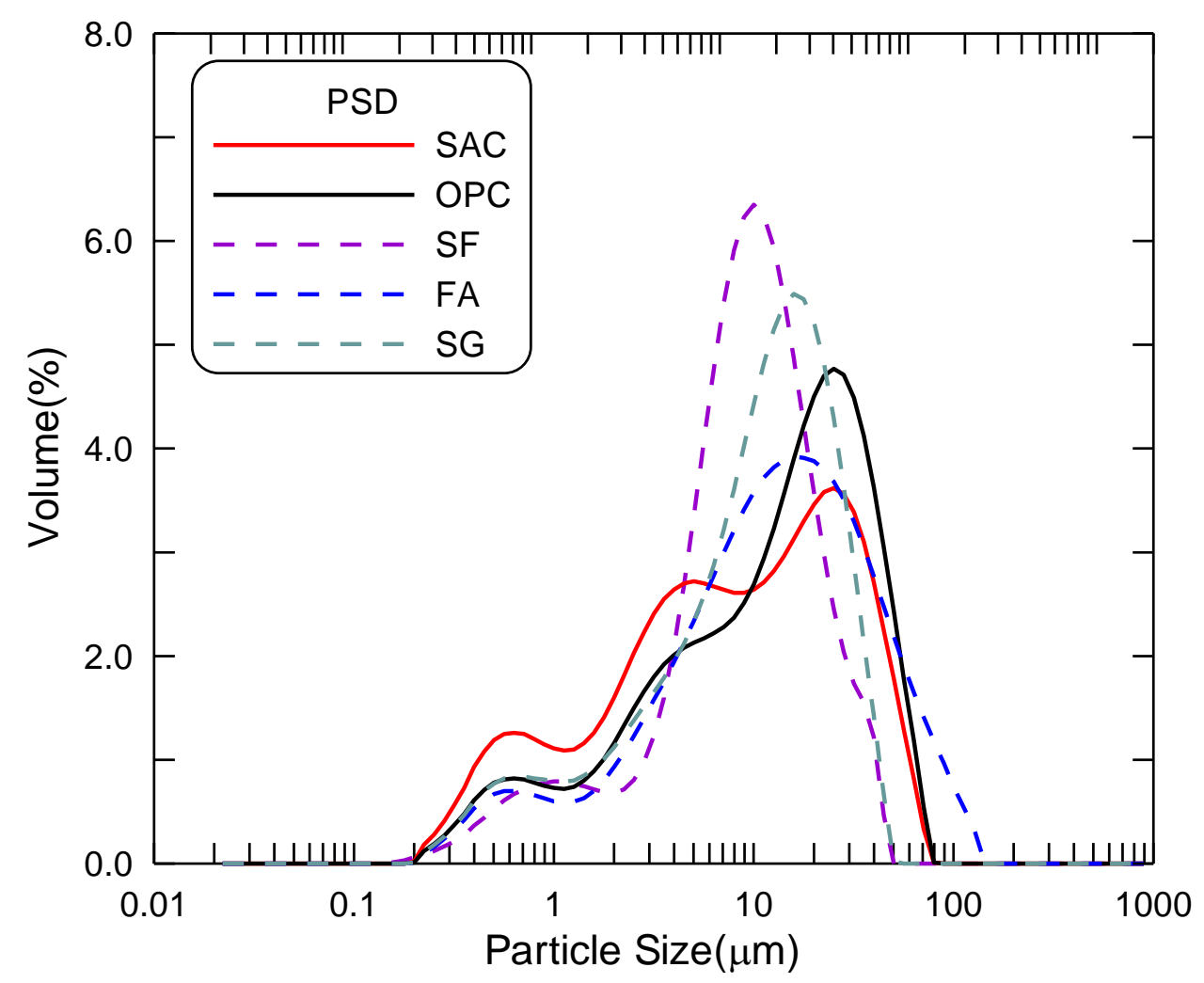

Fig.1 Particle size distribution of the five fine cementitious materials 


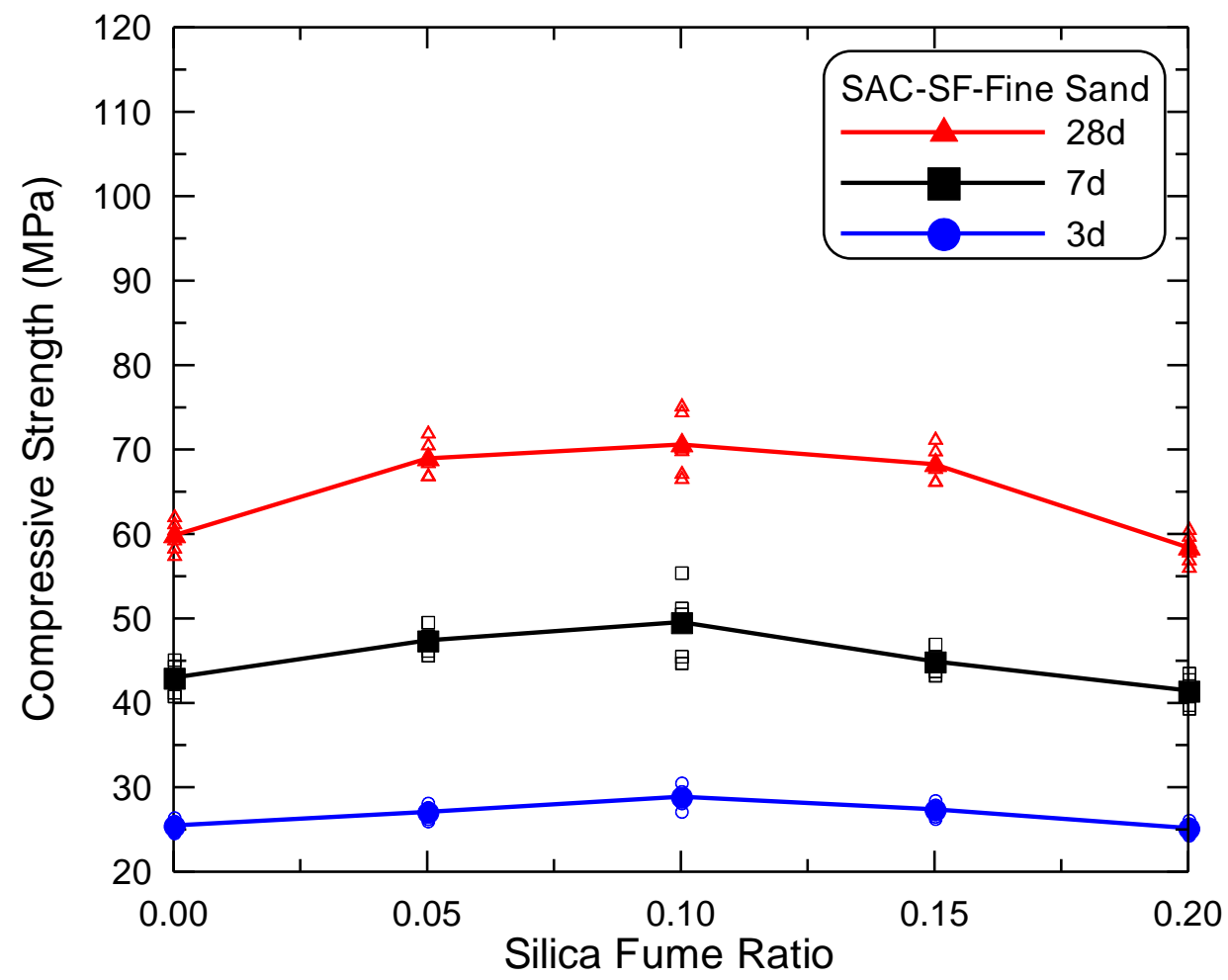

(a)

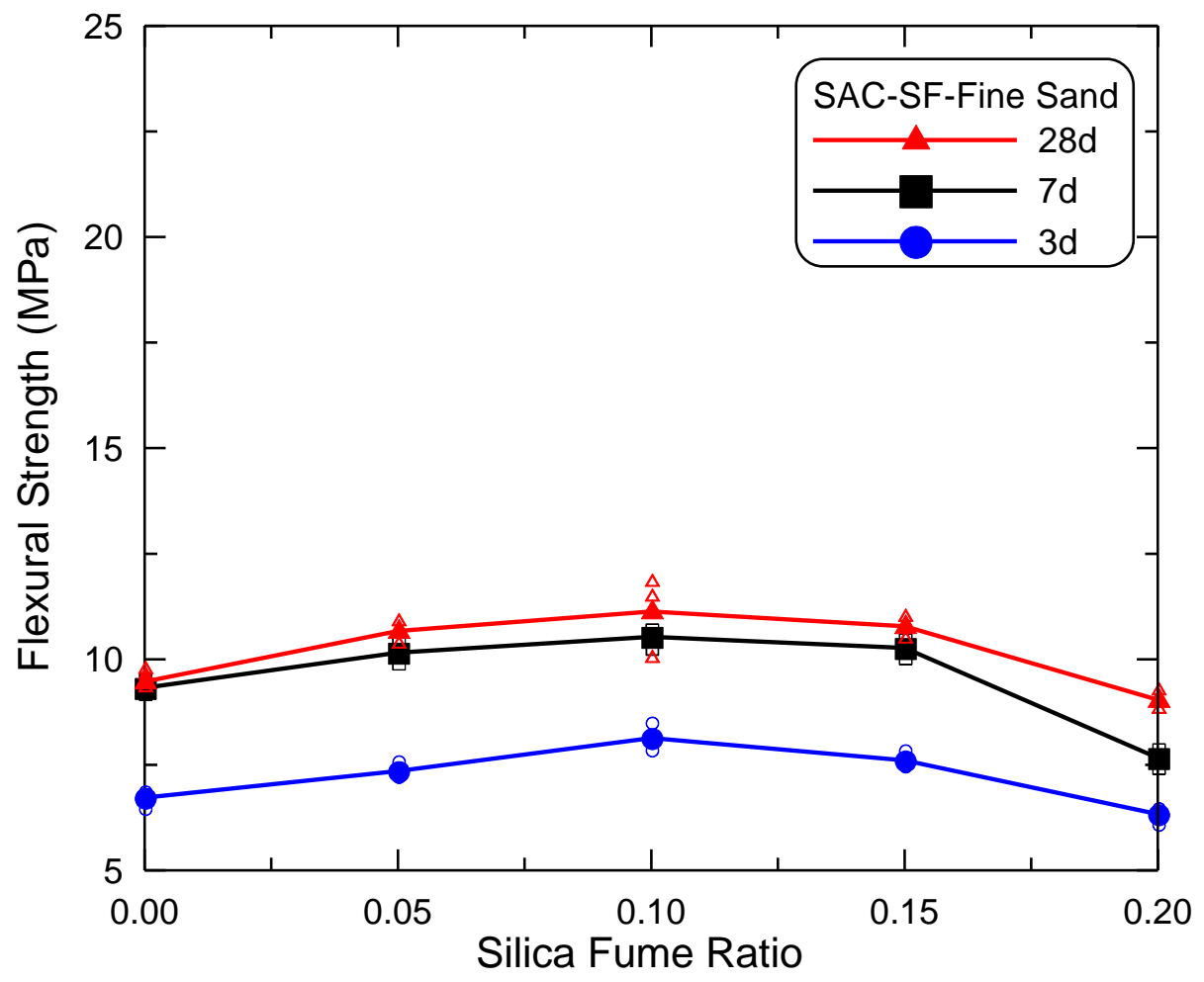

(b)

Fig.2 Effect of silica fume addition on strength of the SAC fine sand mortar, (a) compressive strength, (b) bending strength 


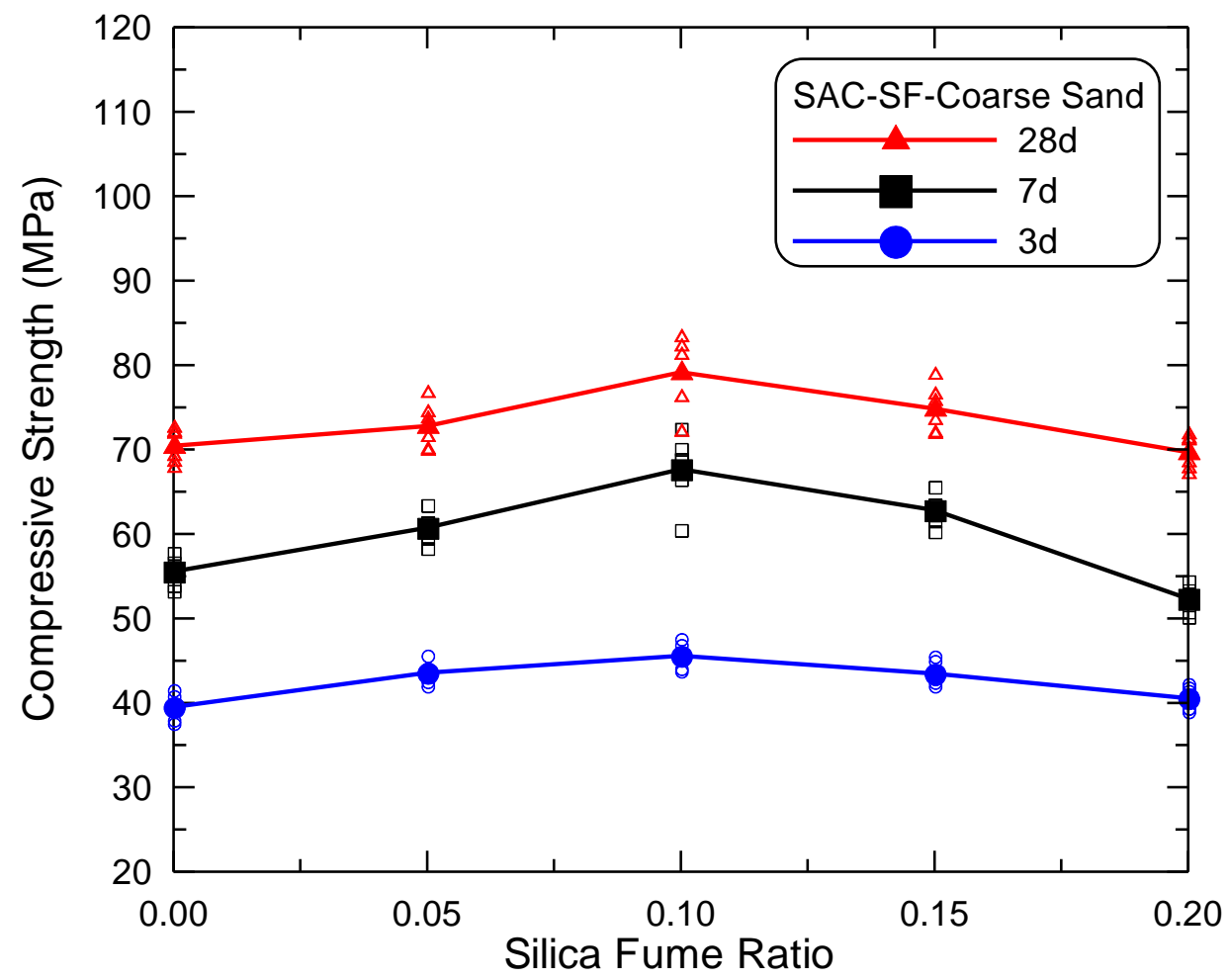

(a)

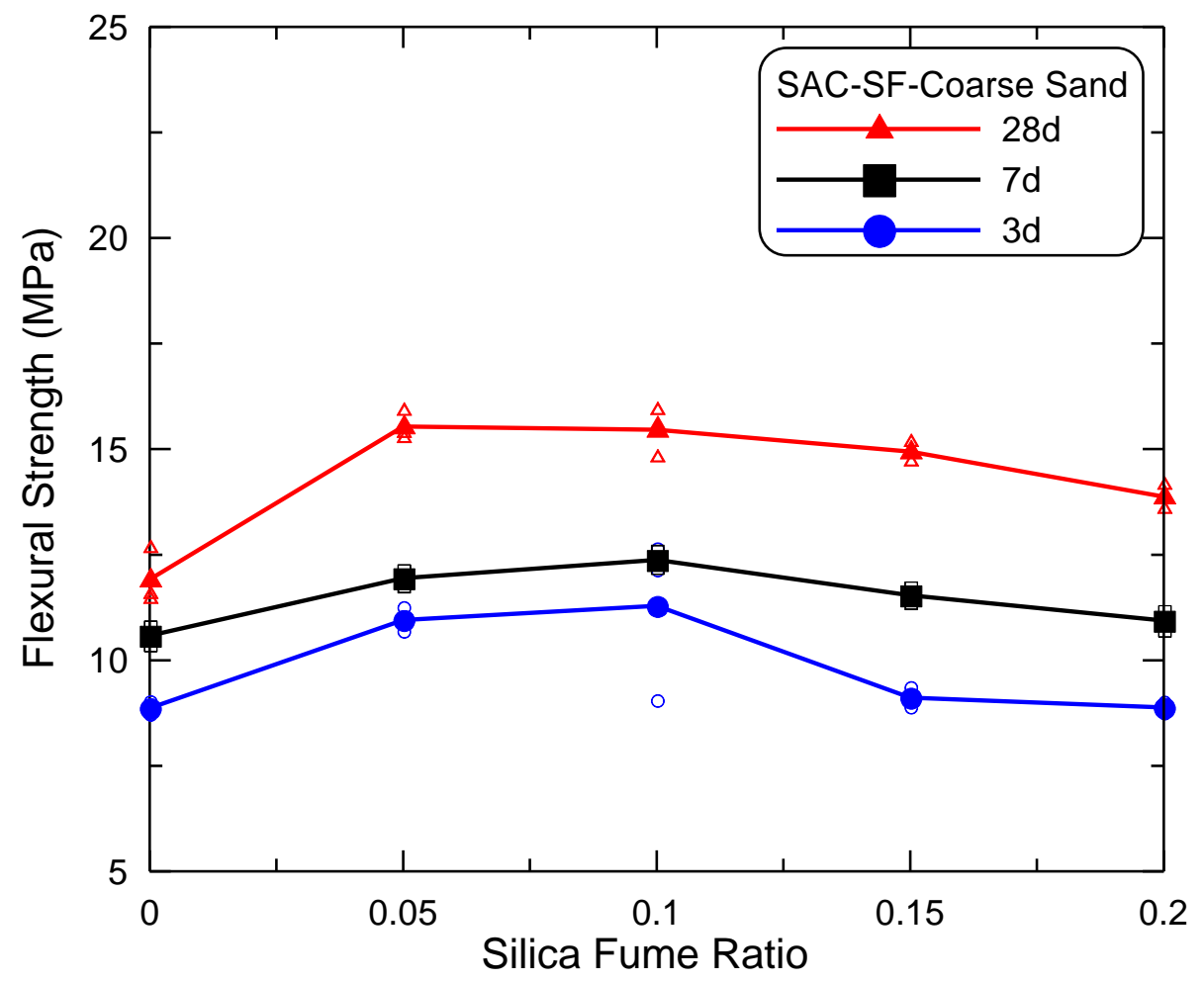

(b)

Fig.3 Effect of silica fume addition on strength of the SAC-coarse sand mortar, (a) compressive strength, (b) bending strength 


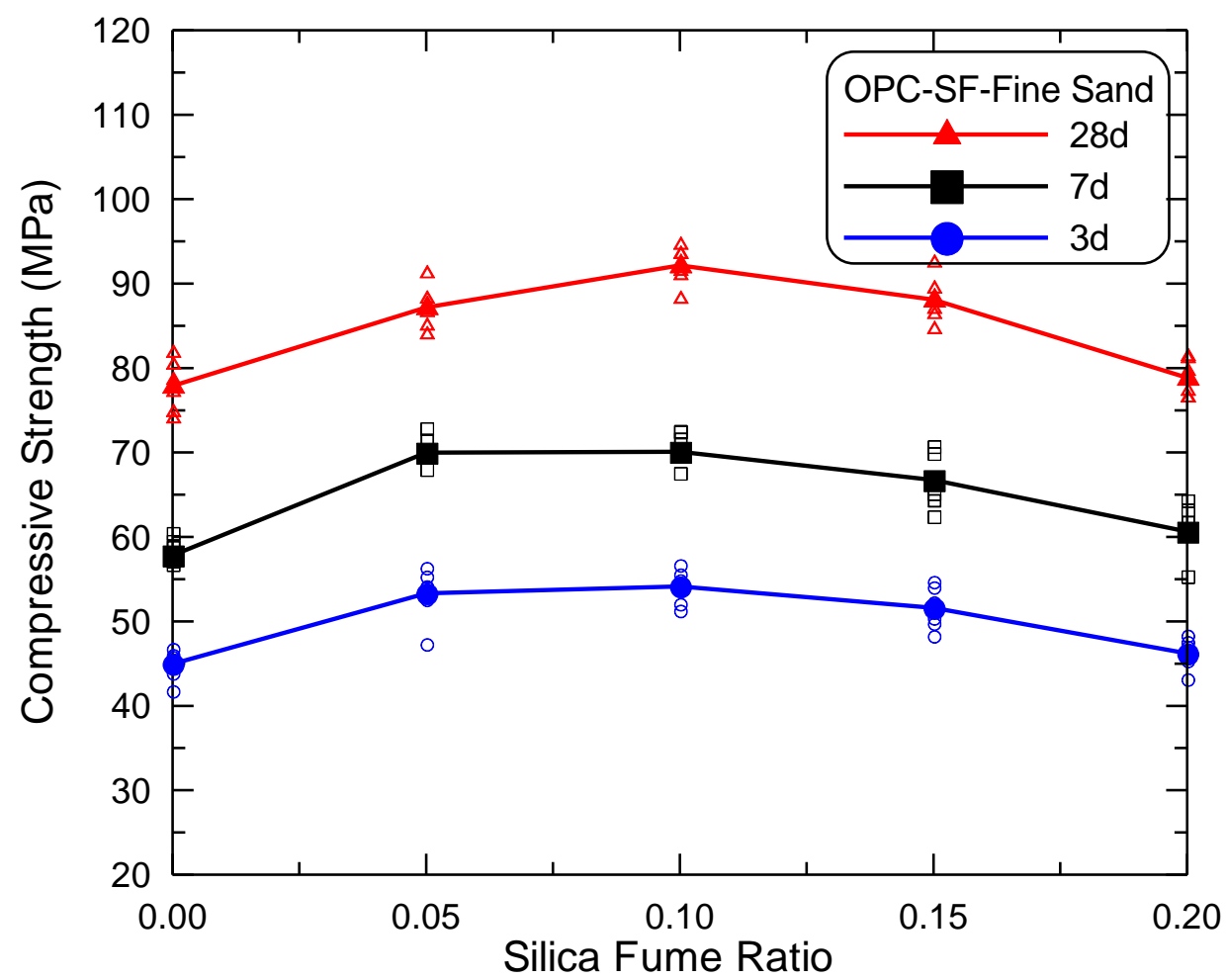

(a)

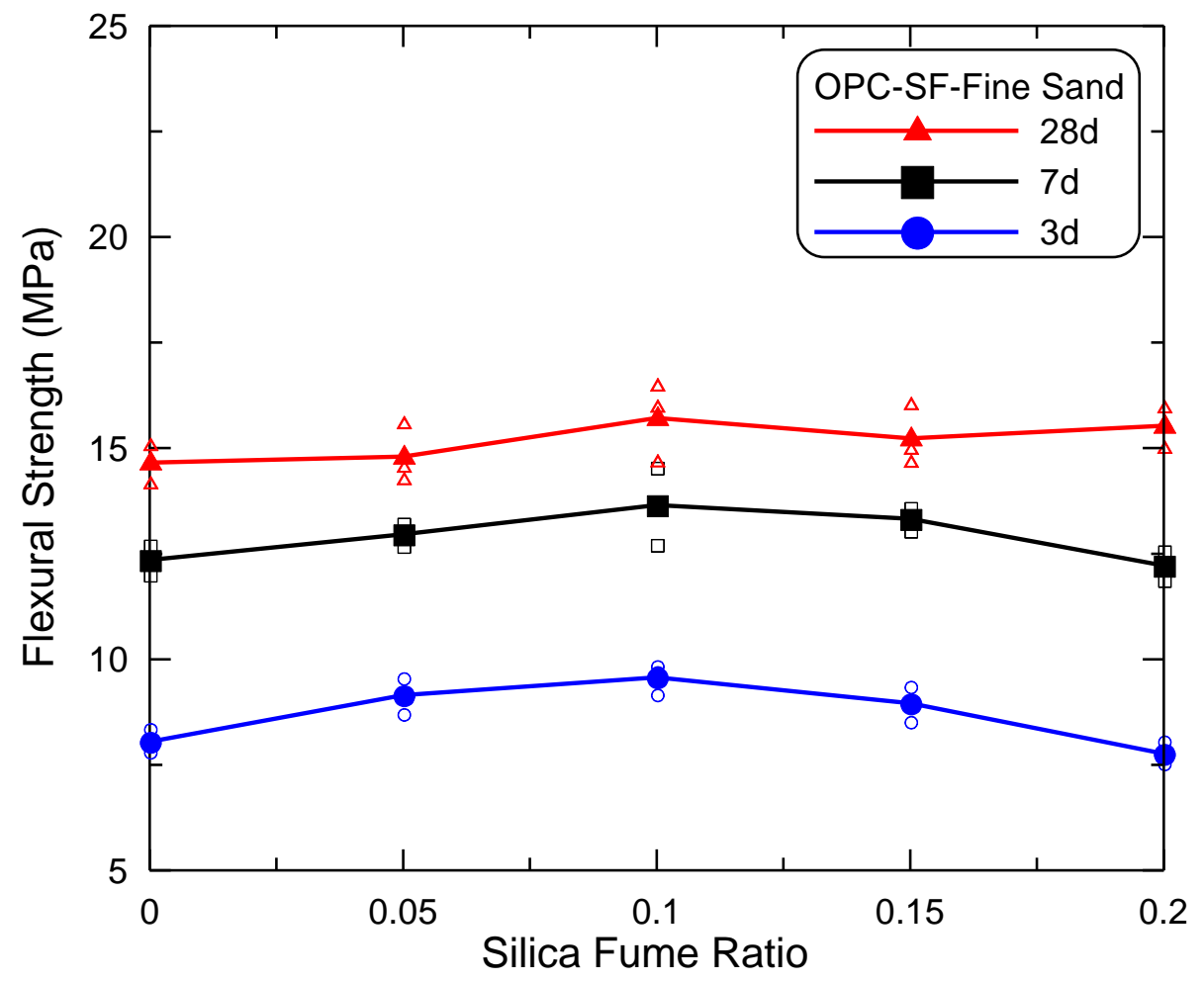

(b)

Fig.4 Effect of silica fume addition on strength of OPC-fine sand mortar, (a) compressive strength, (b) bending strength 


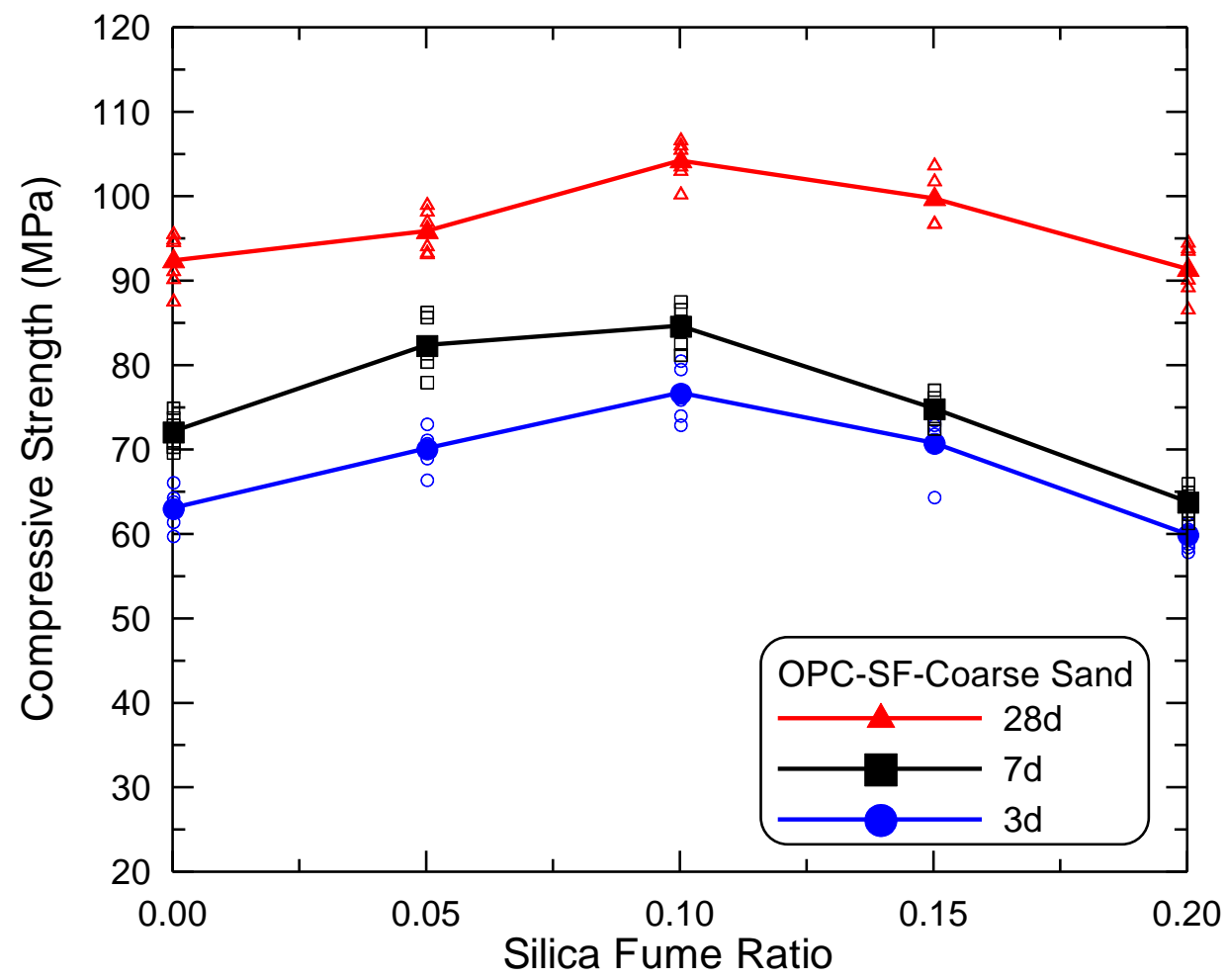

(a)

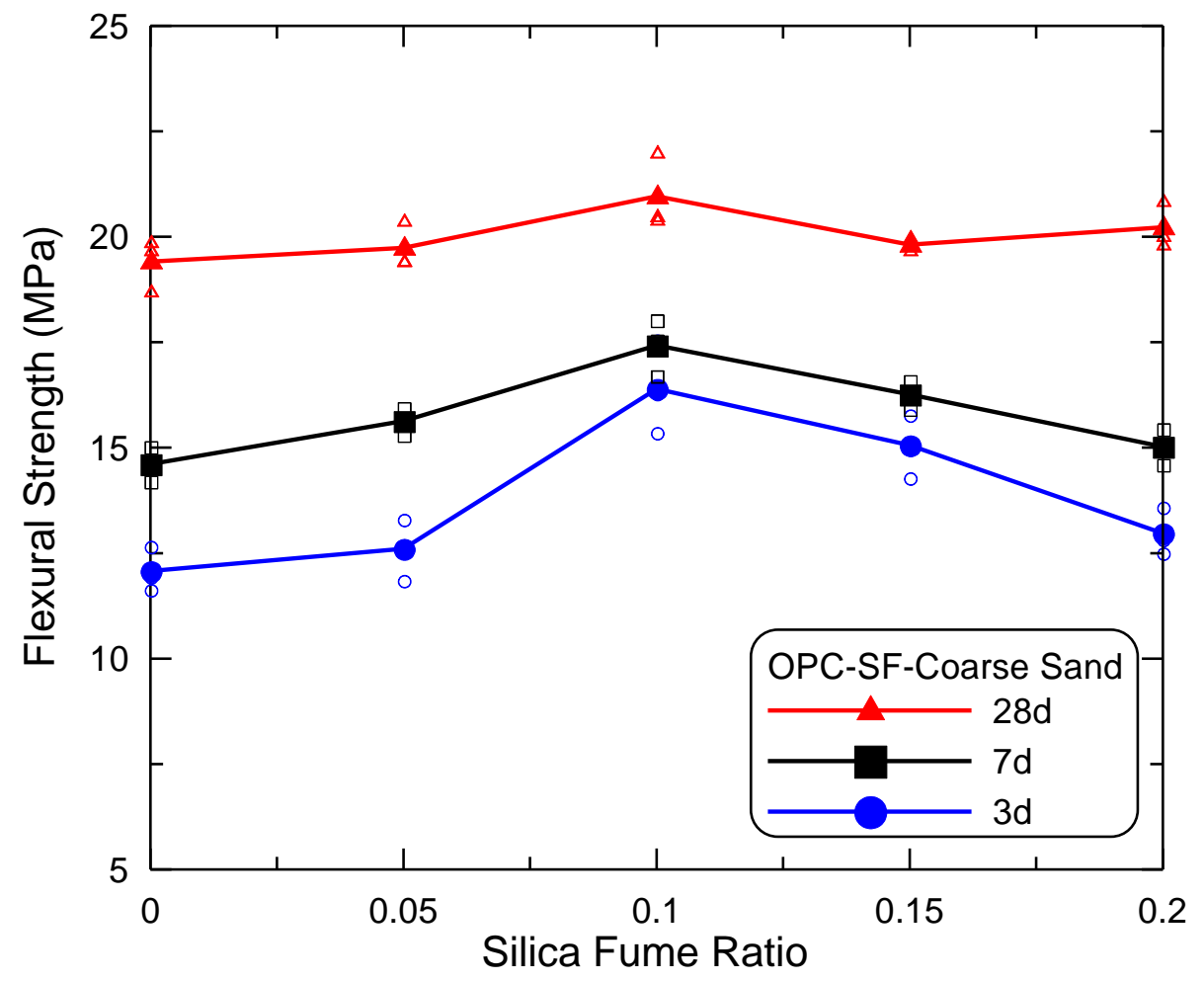

(b)

Fig.5 Effect of silica fume addition on strength of OPC-coarse sand mortar, (a) compressive strength, (b) bending strength 


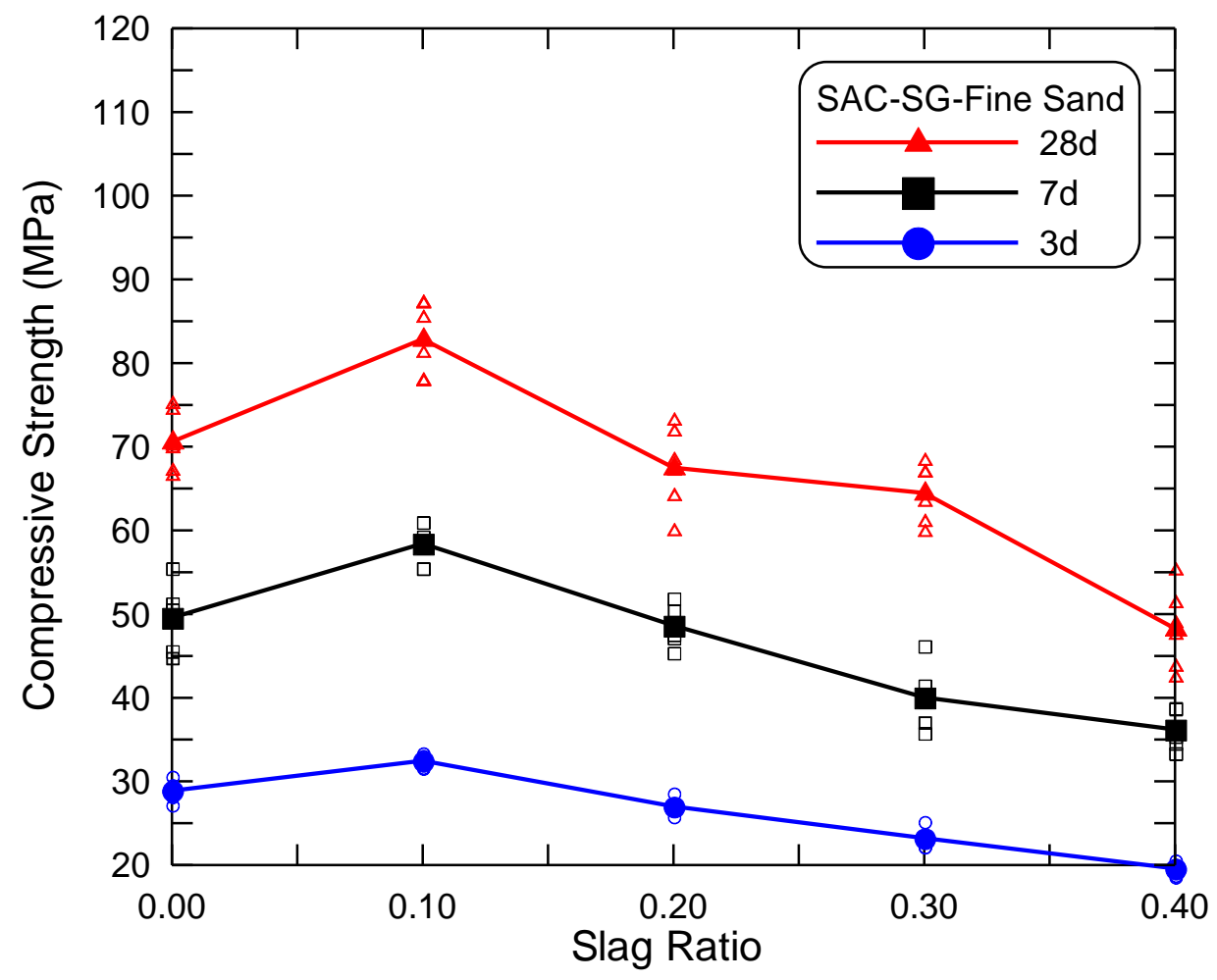

(a)

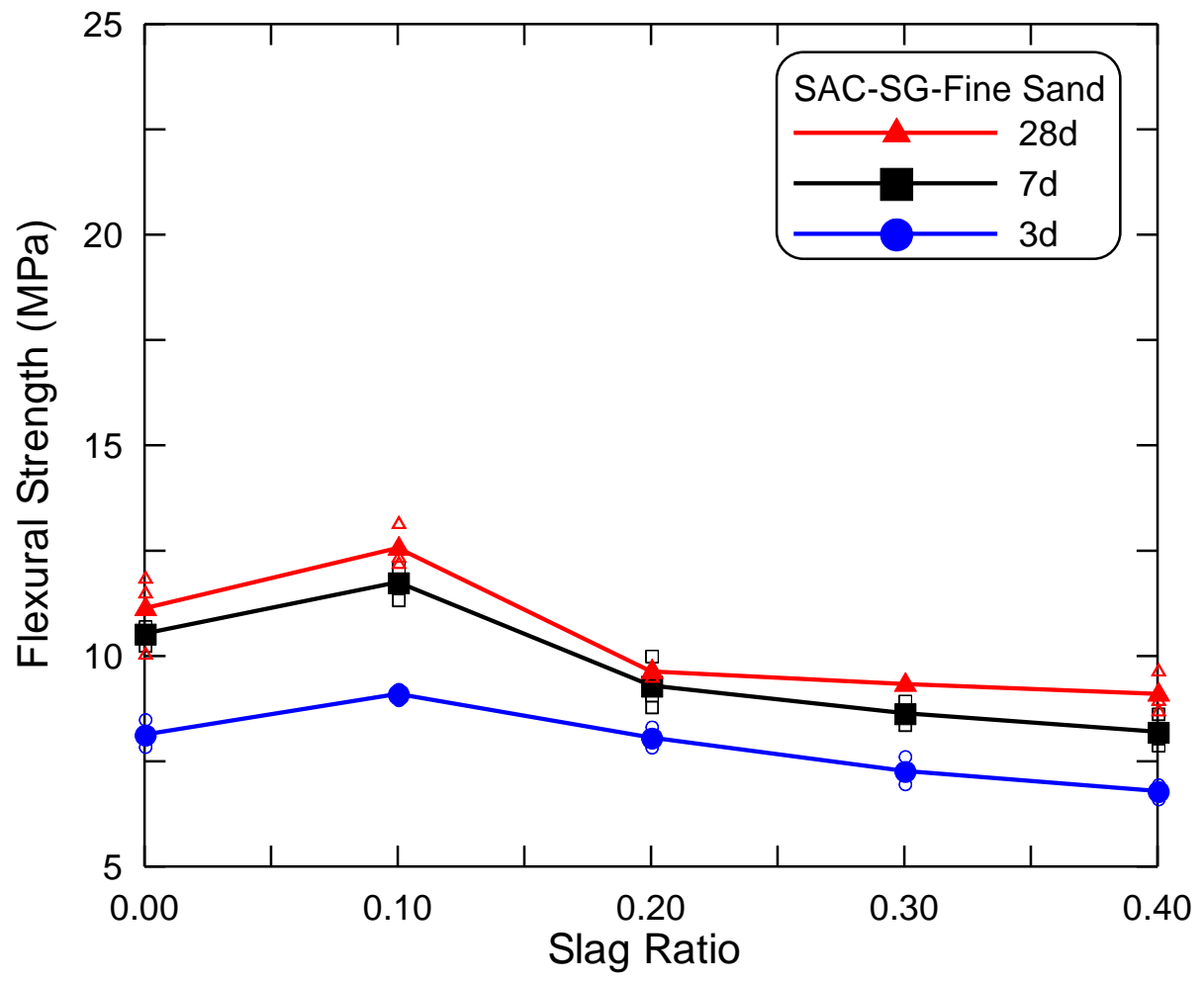

(b)

Fig.6 Effect of slag addition on strength of the SAC-fine sand mortar, (a) compressive strength, (b) bending strength 


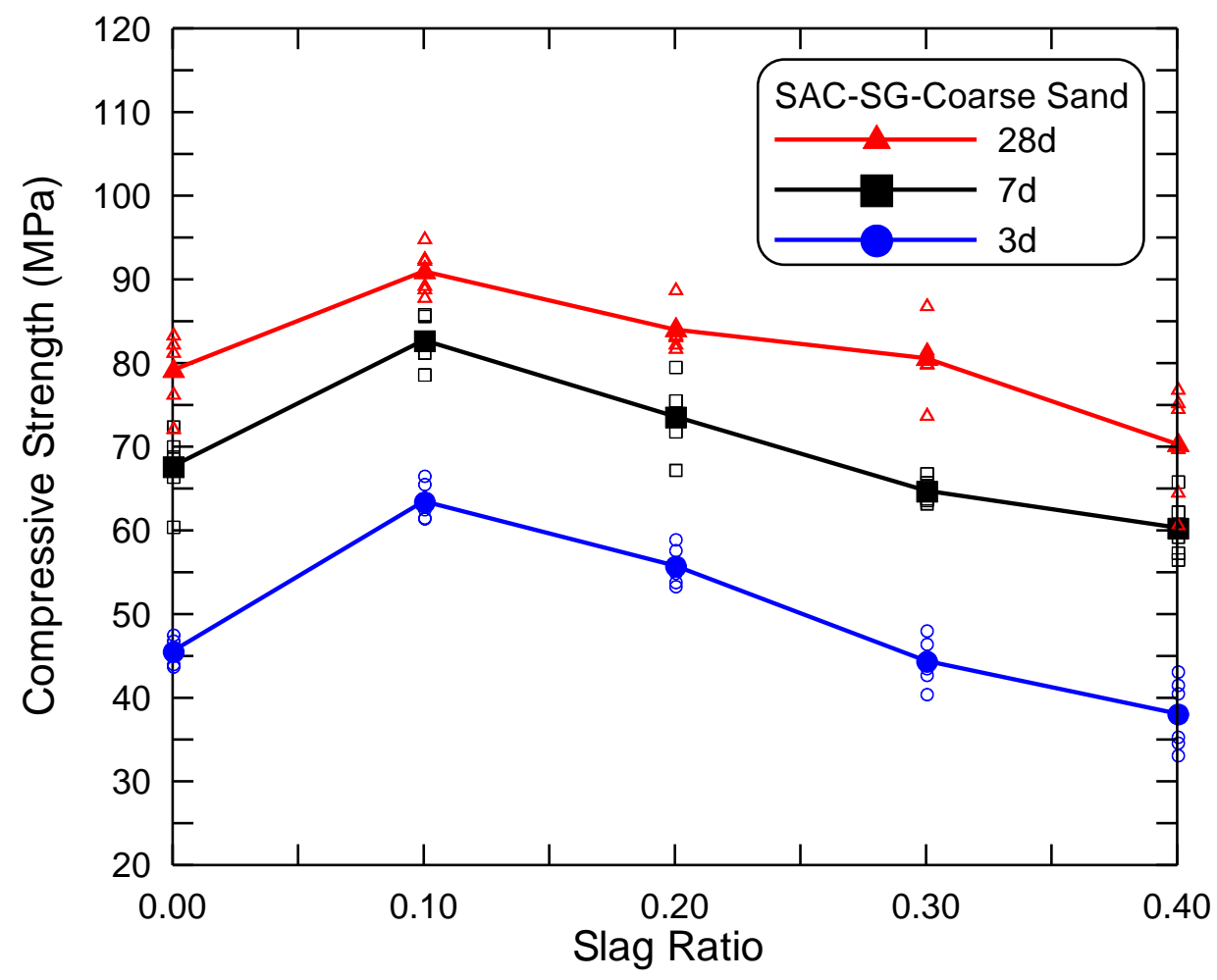

(a)

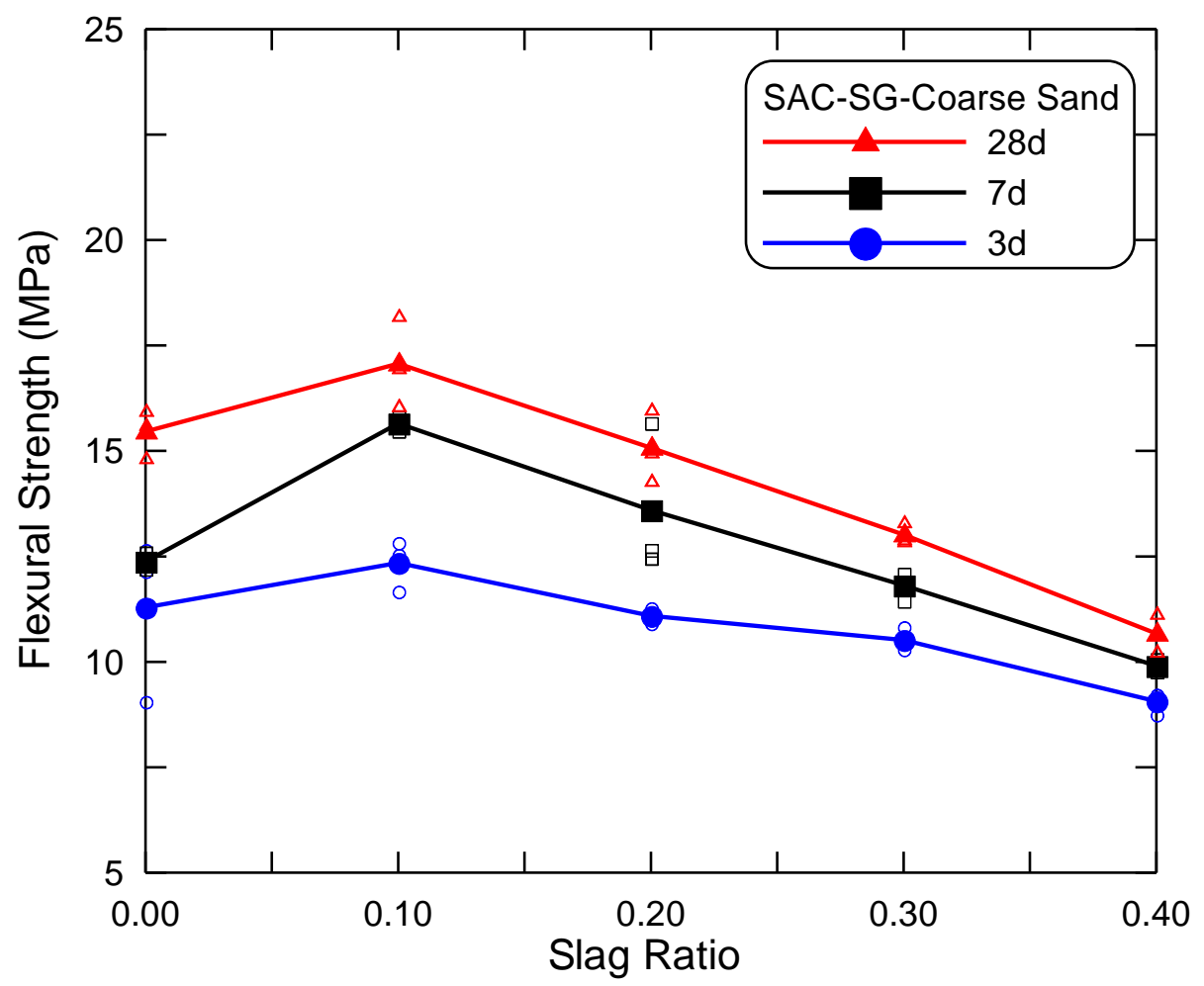

(b)

Fig.7 Effect of slag addition on strength of SAC-coarse sand mortar, (a) compressive strength, (b) bending strength 


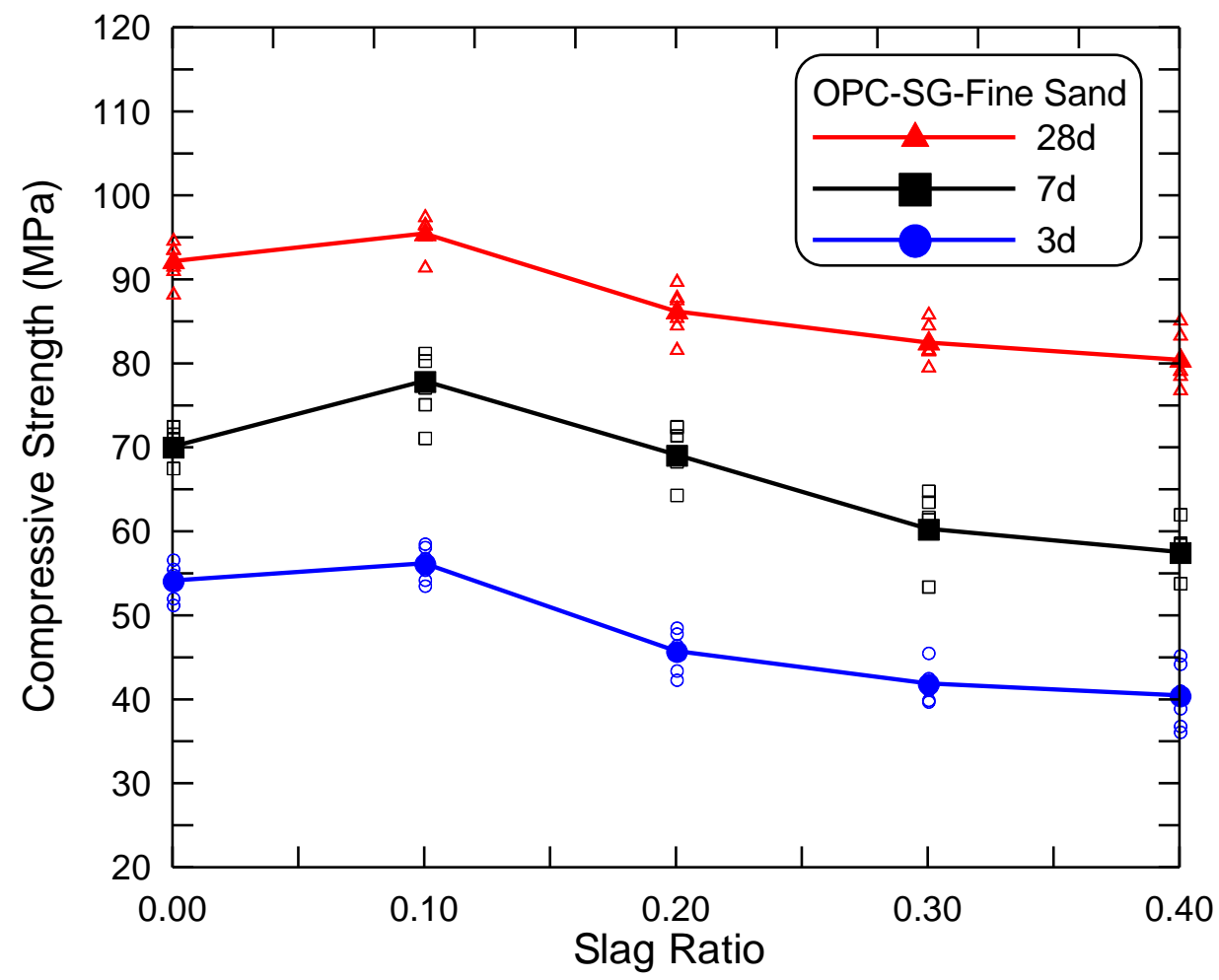

(a)

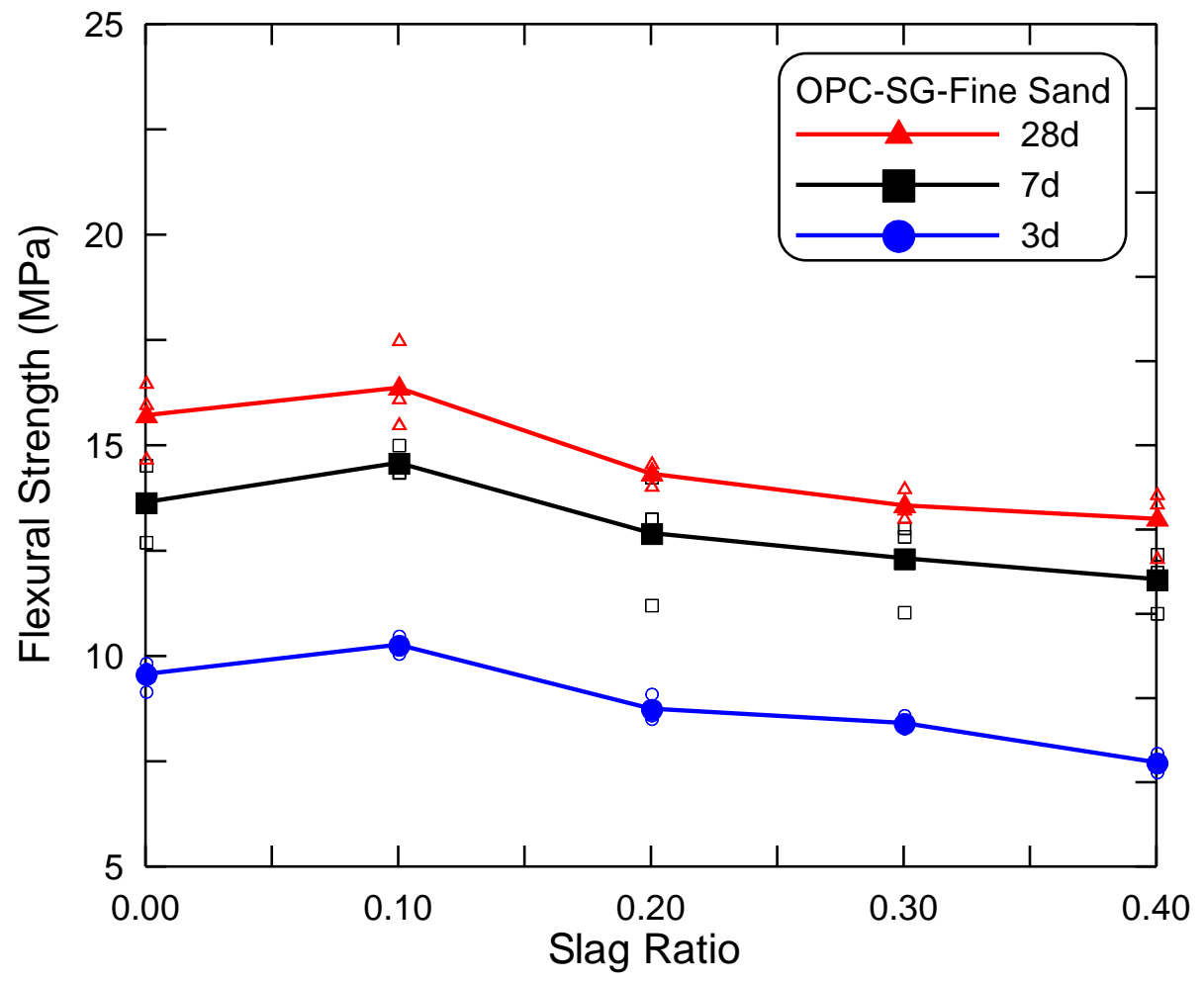

(b)

Fig. 8 Effect of slag addition on strength of the OPC-fine sand mortar, (a) compressive strength, (b) bending strength 


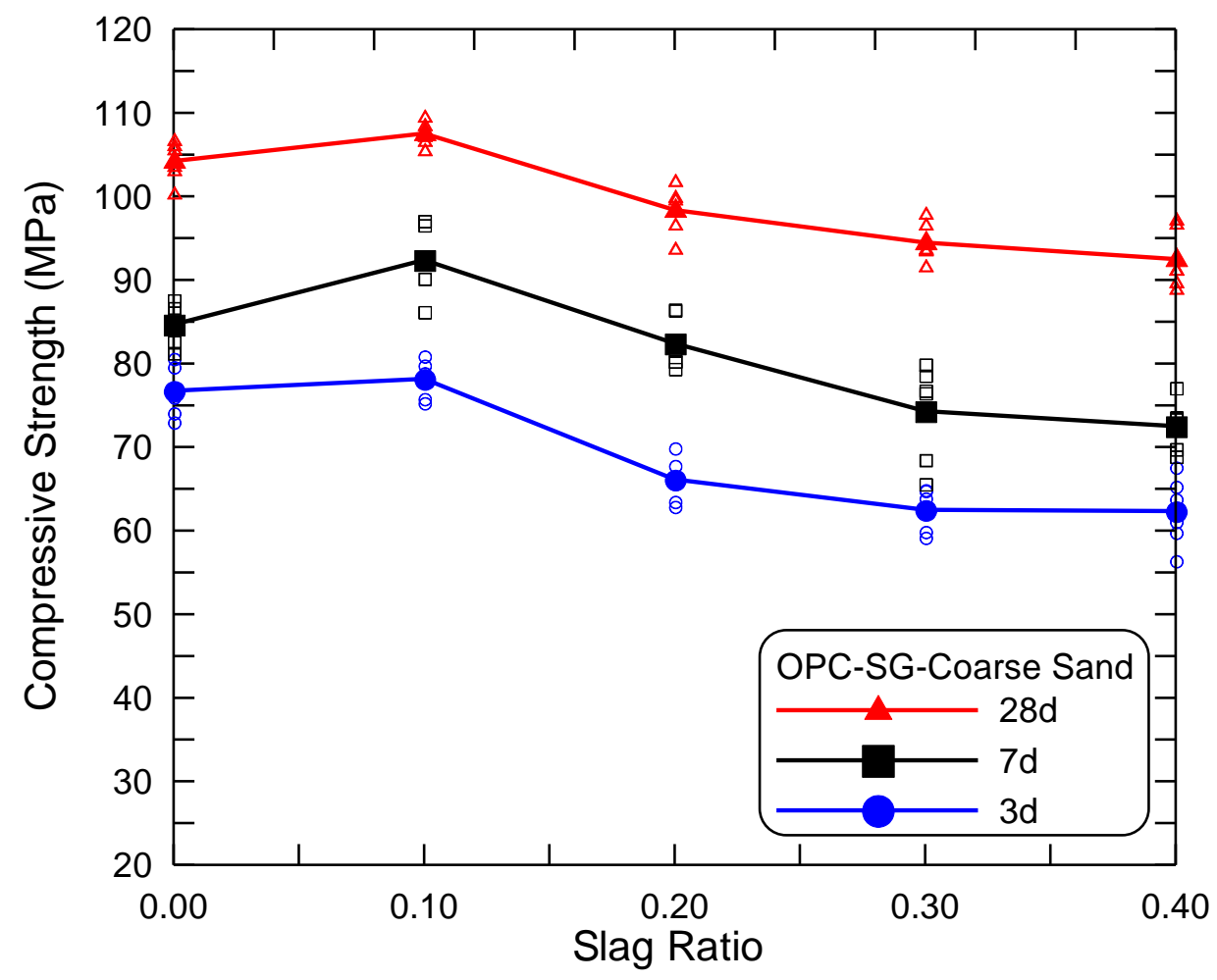

(a)

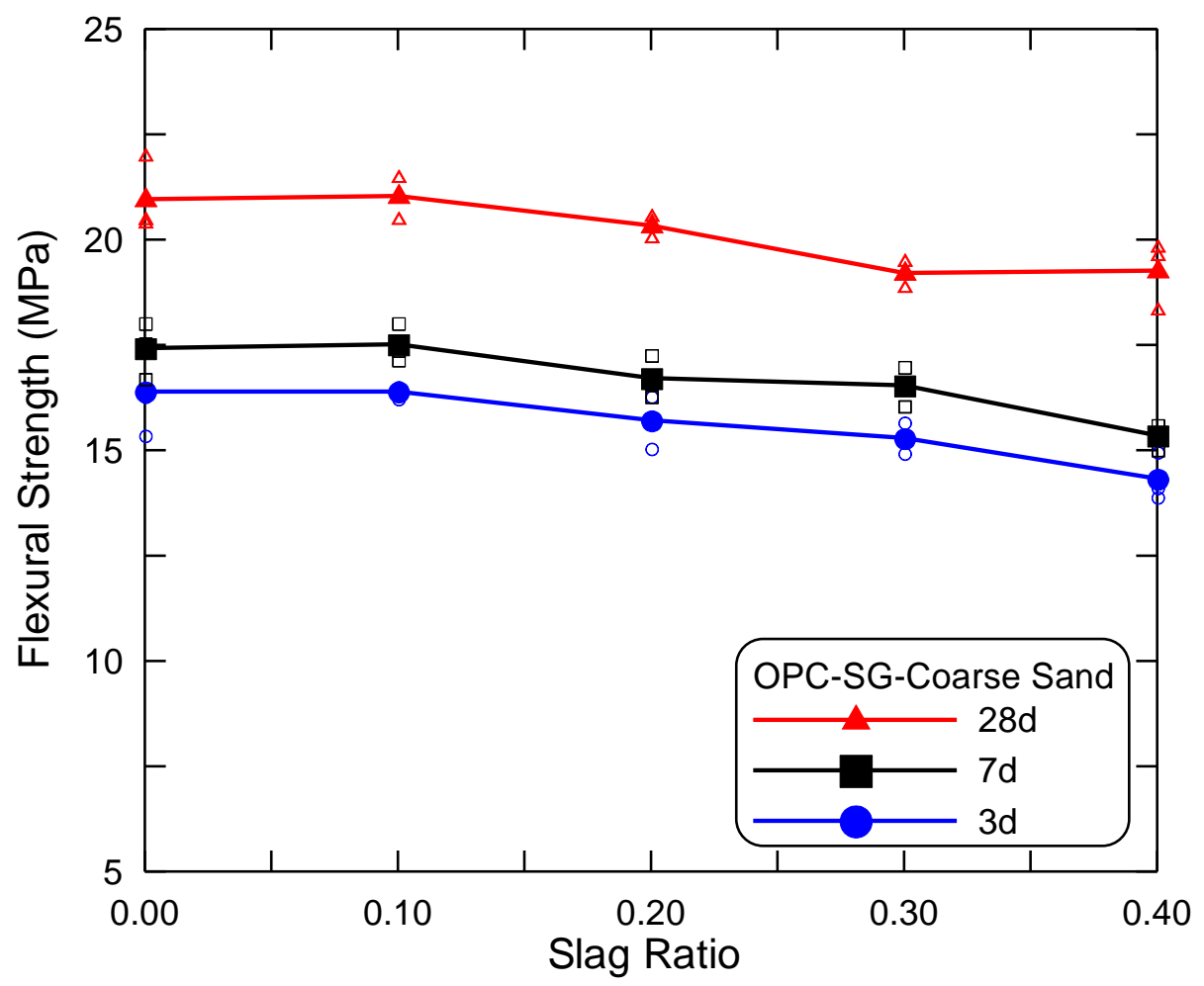

(b)

Fig.9 Effect of slag addition on strength of OPC-coarse sand mortar, (a) compressive strength, (b) bending strength 


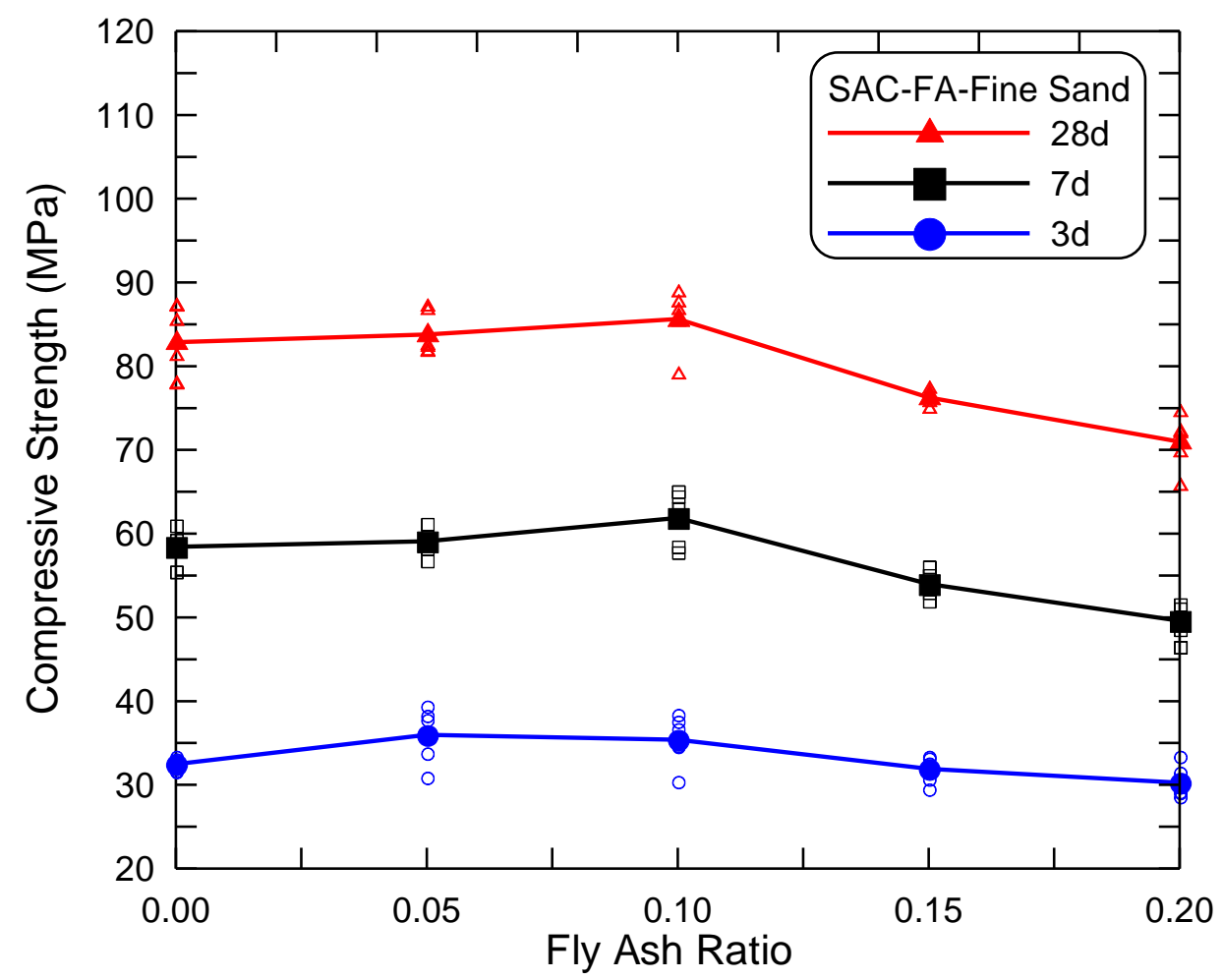

(a)

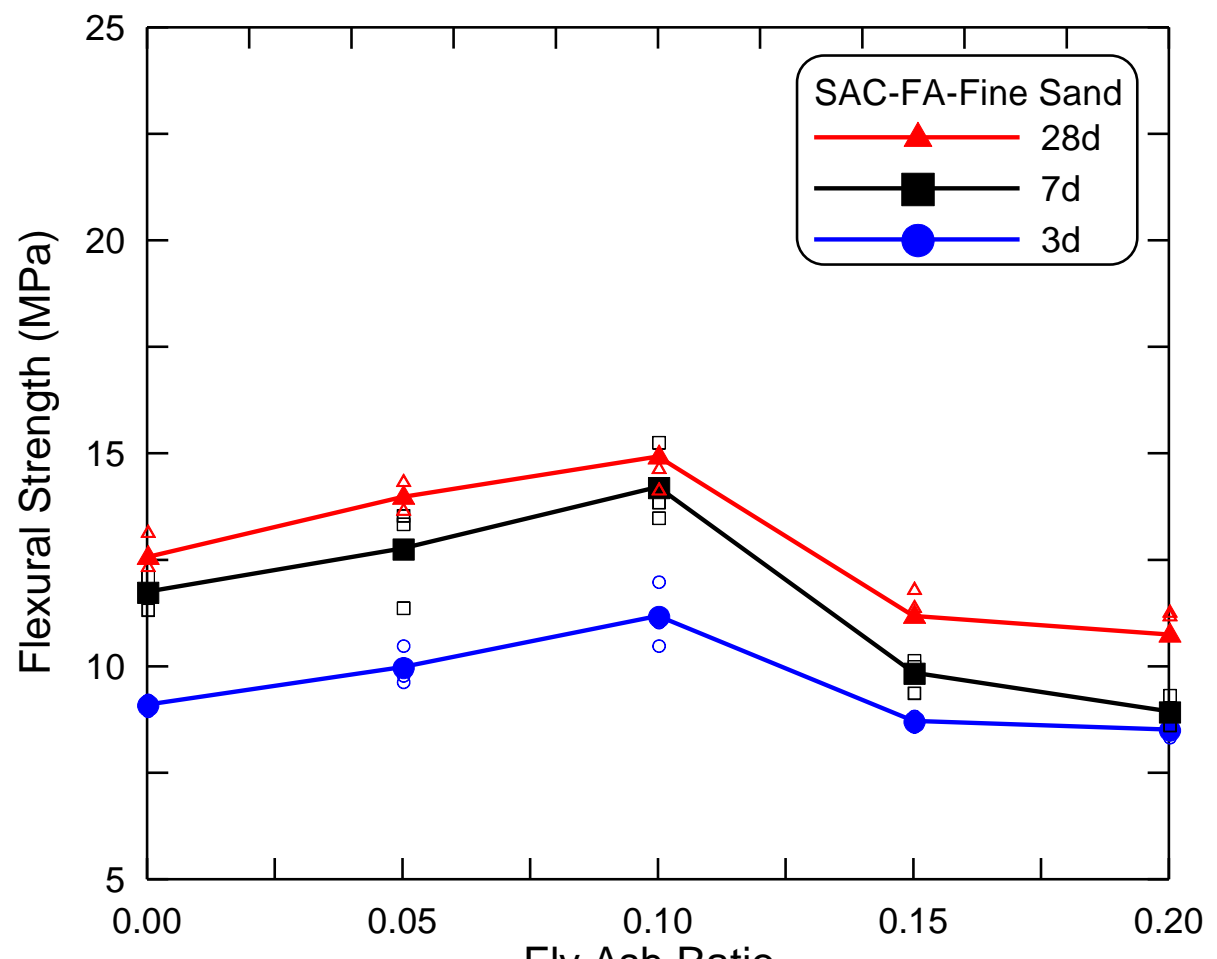

Fly Ash Ratio

(b)

Fig.10 Effect of fly ash addition on strength of the SAC-fine sand mortar, (a) compressive strength, (b) bending strength 


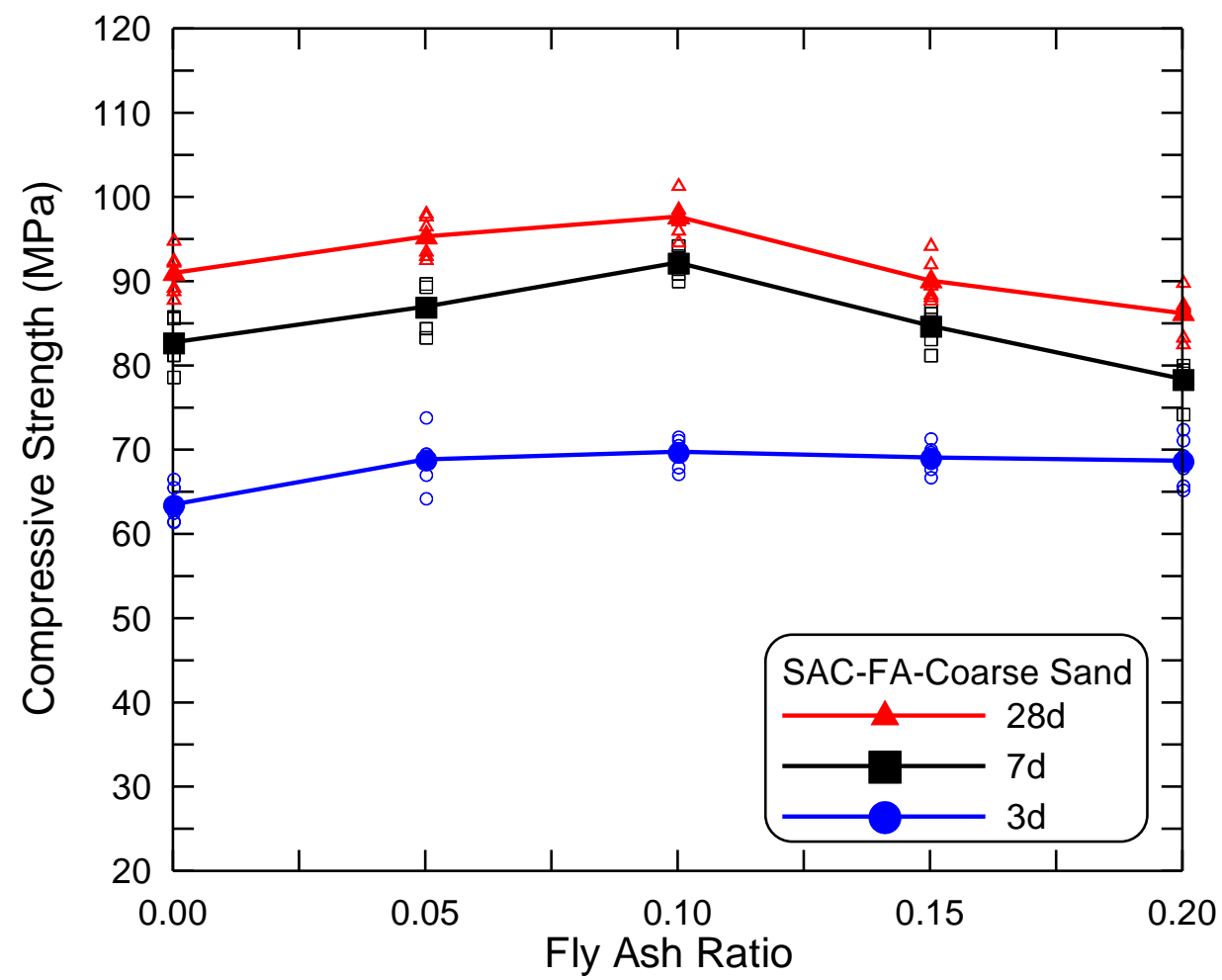

(a)

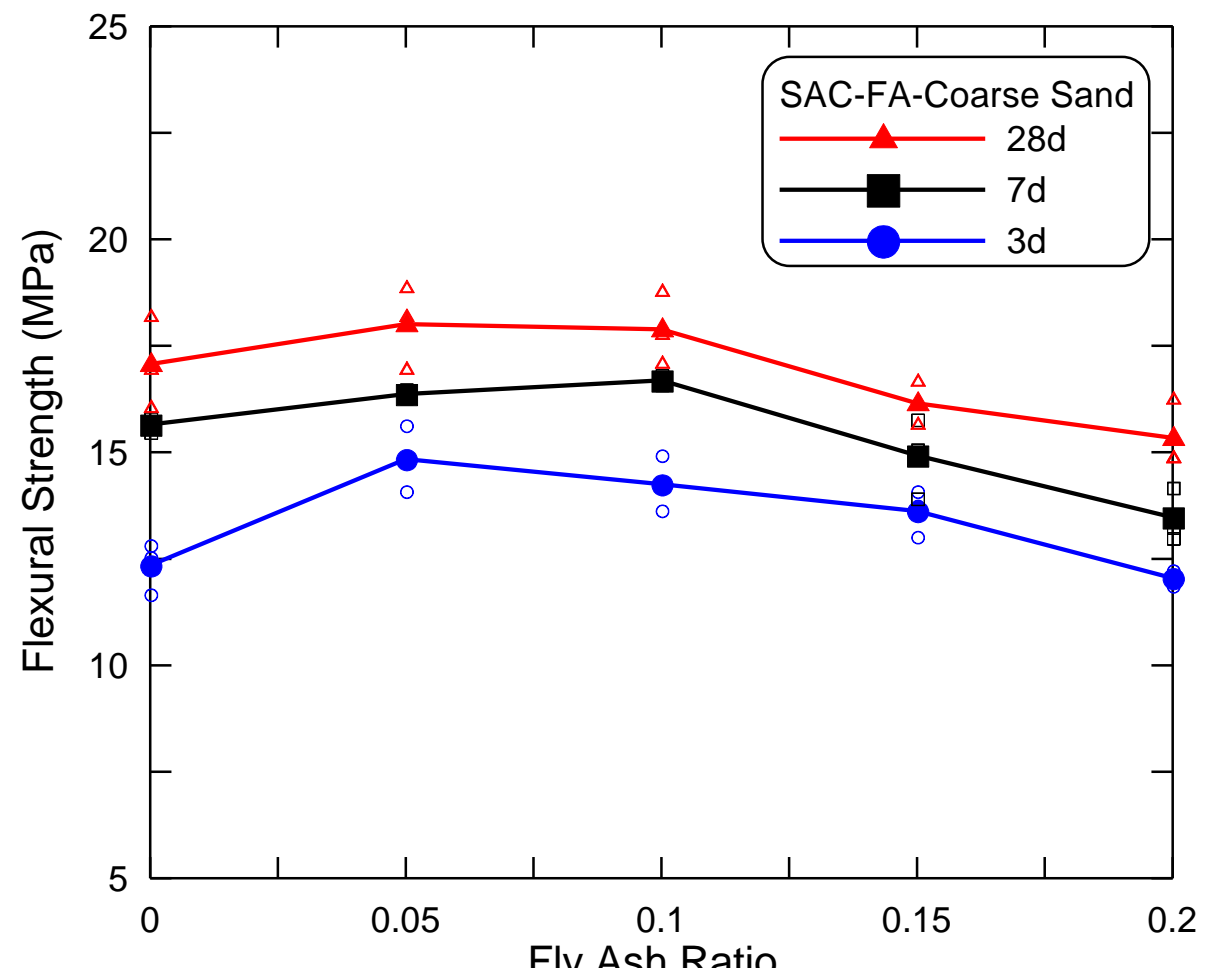

(b)

Fig.11 Effect of fly ash addition on strength of the SAC-coarse sand mortar, (a) compressive strength, (b) bending strength 


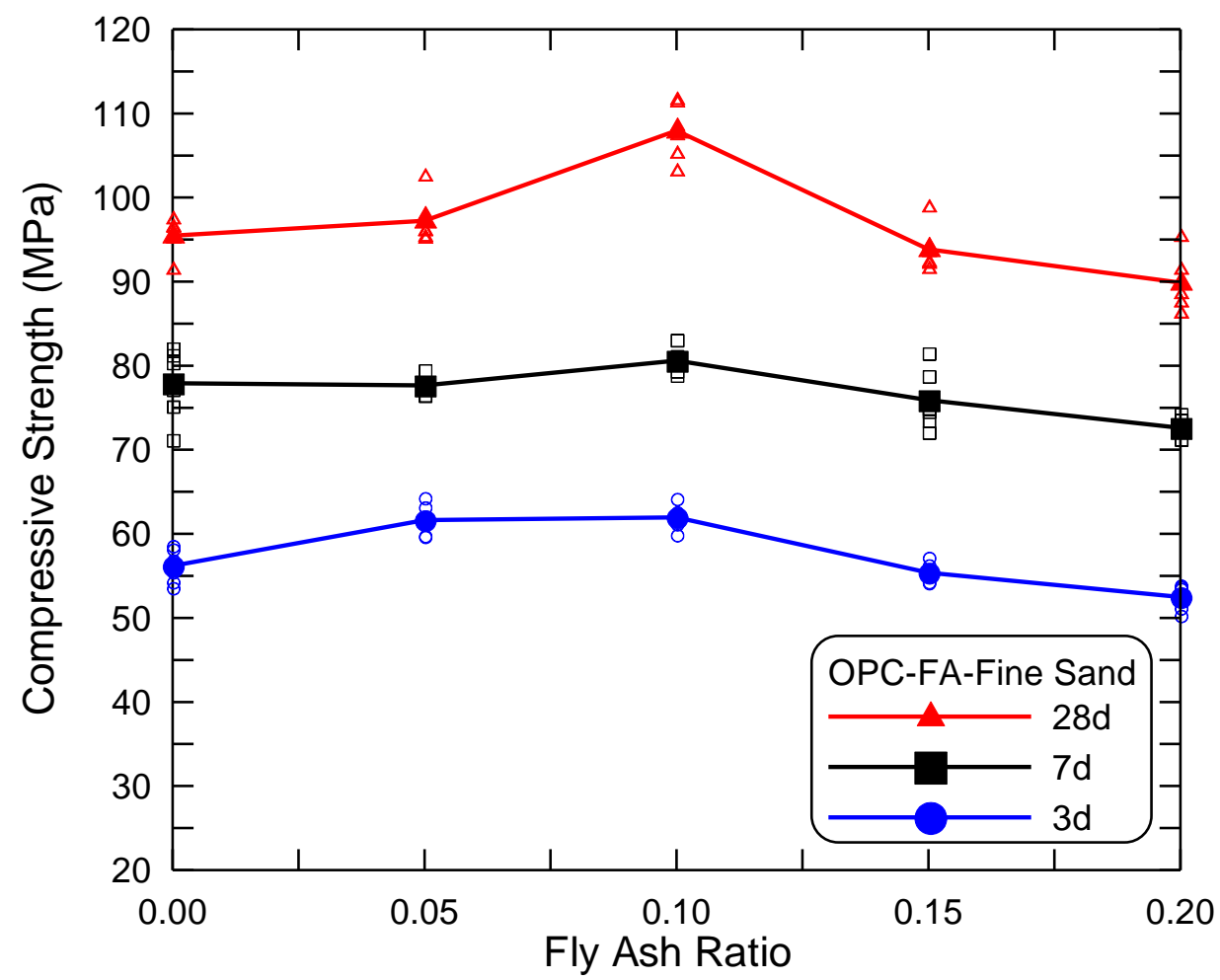

(a)

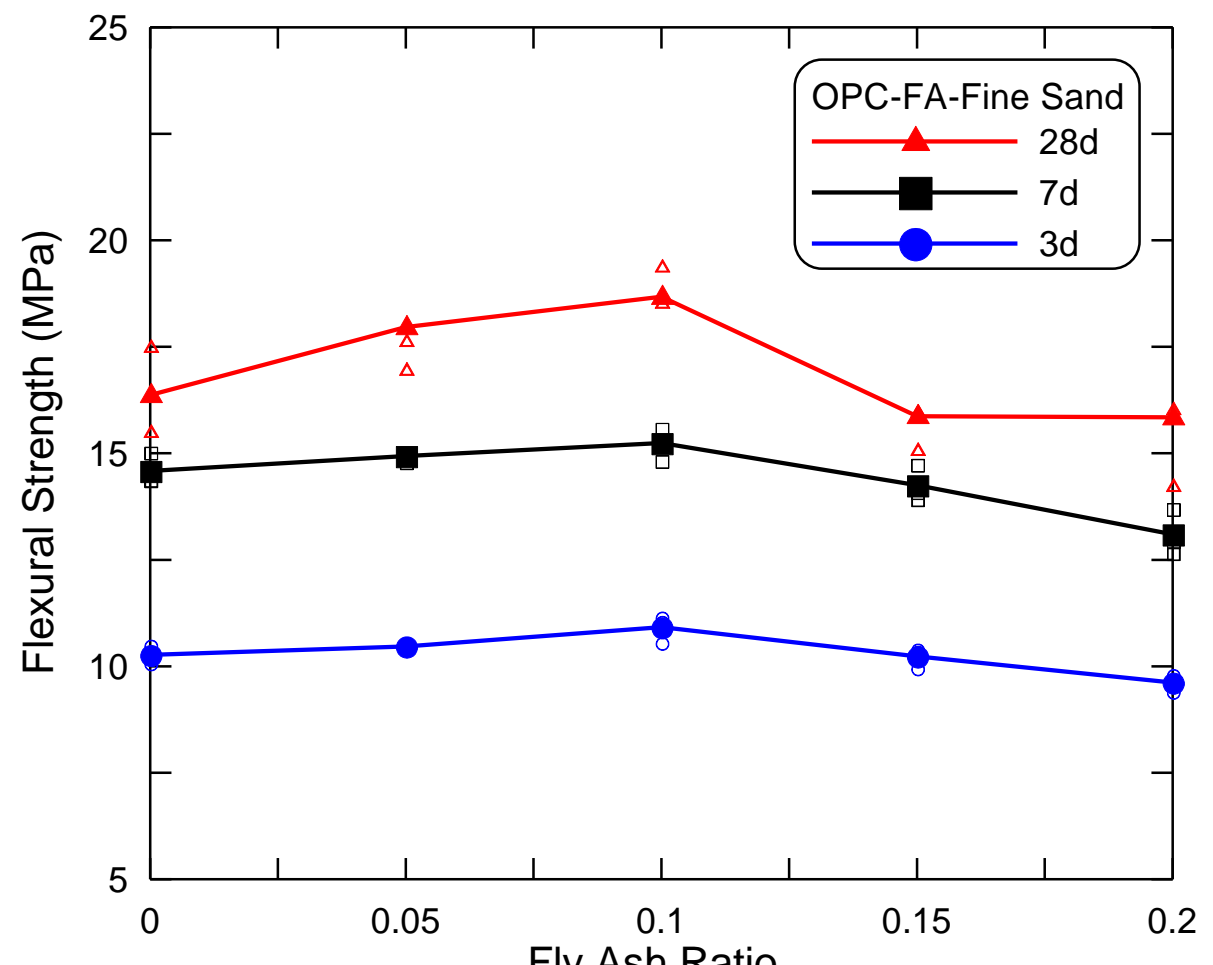

(b)

Fig.12 Effect of fly ash addition on strength of the OPC-fine sand mortar, (a) compressive strength, (b) bending strength 


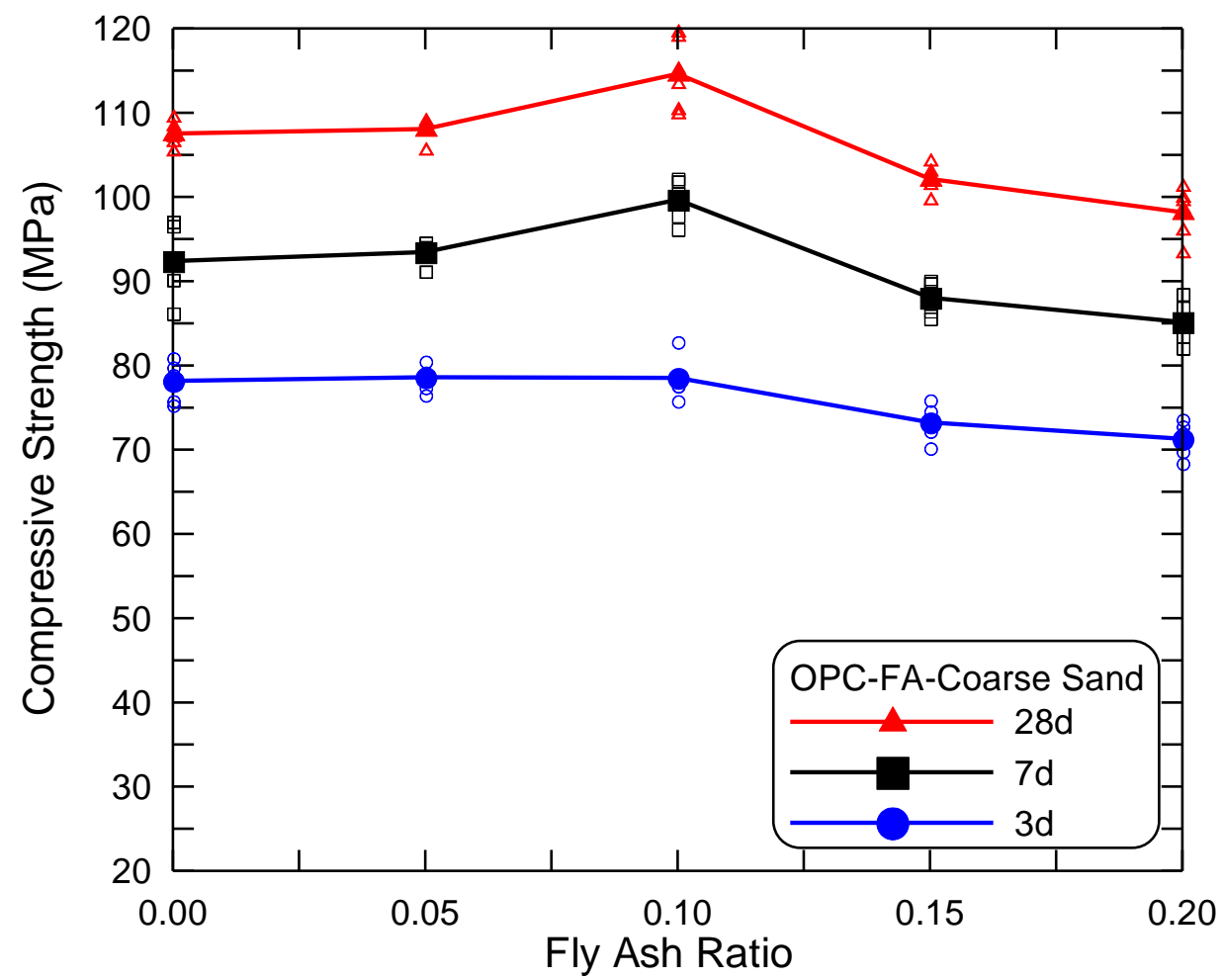

(a)

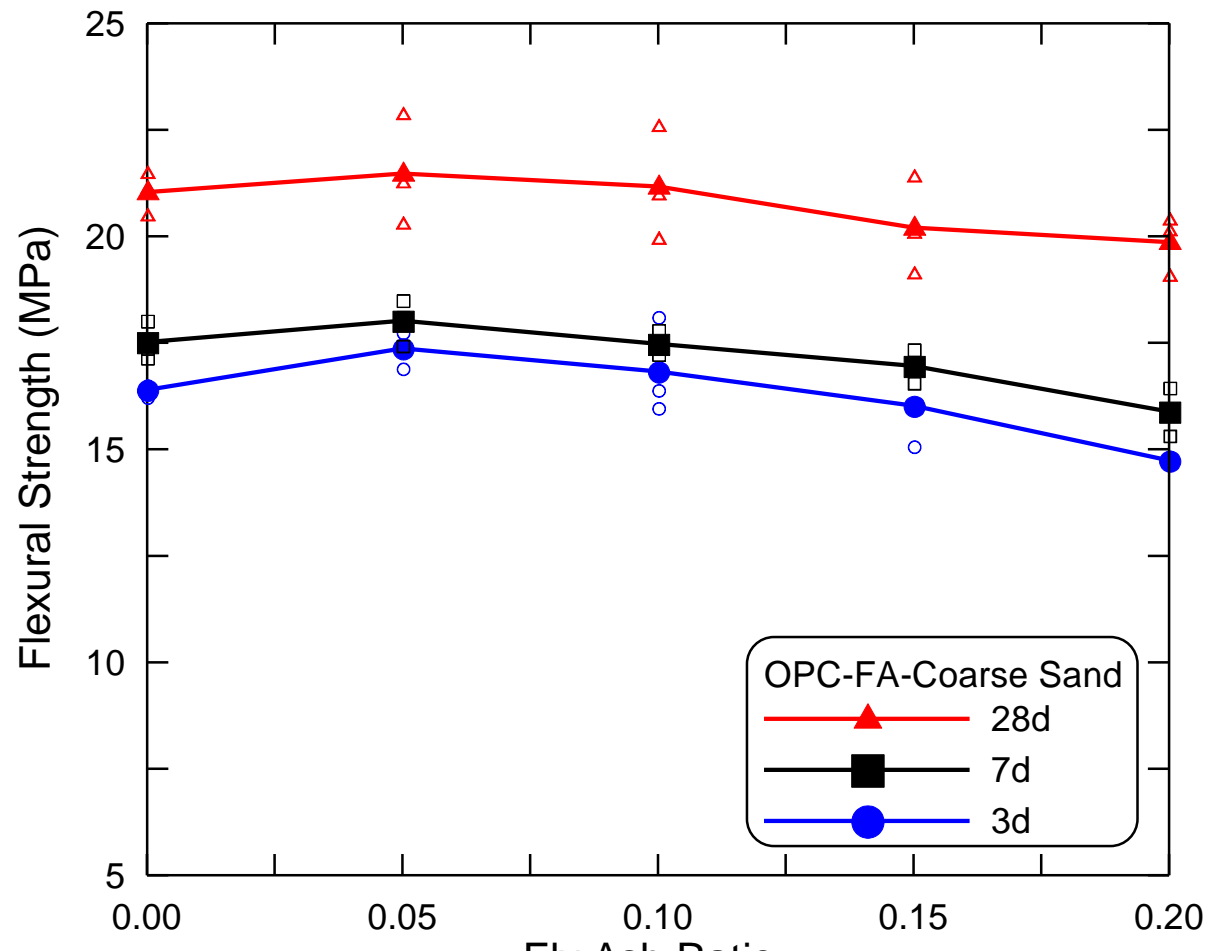

Fly Ash Ratio

(b)

Fig.13 Effect of fly ash addition on strength of the OPC-coarse sand mortar, (a) compressive strength, (b) bending strength 


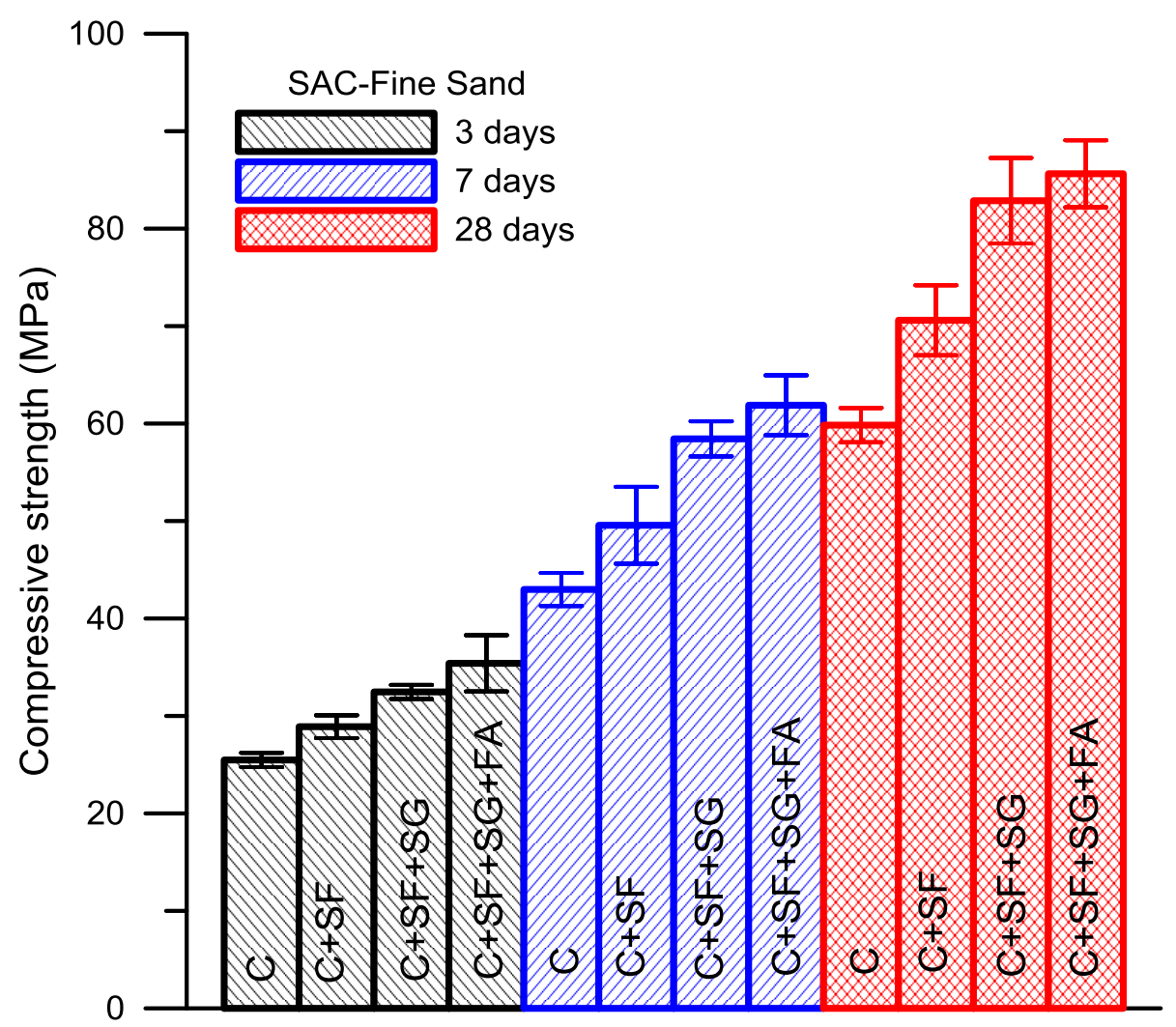

(a)

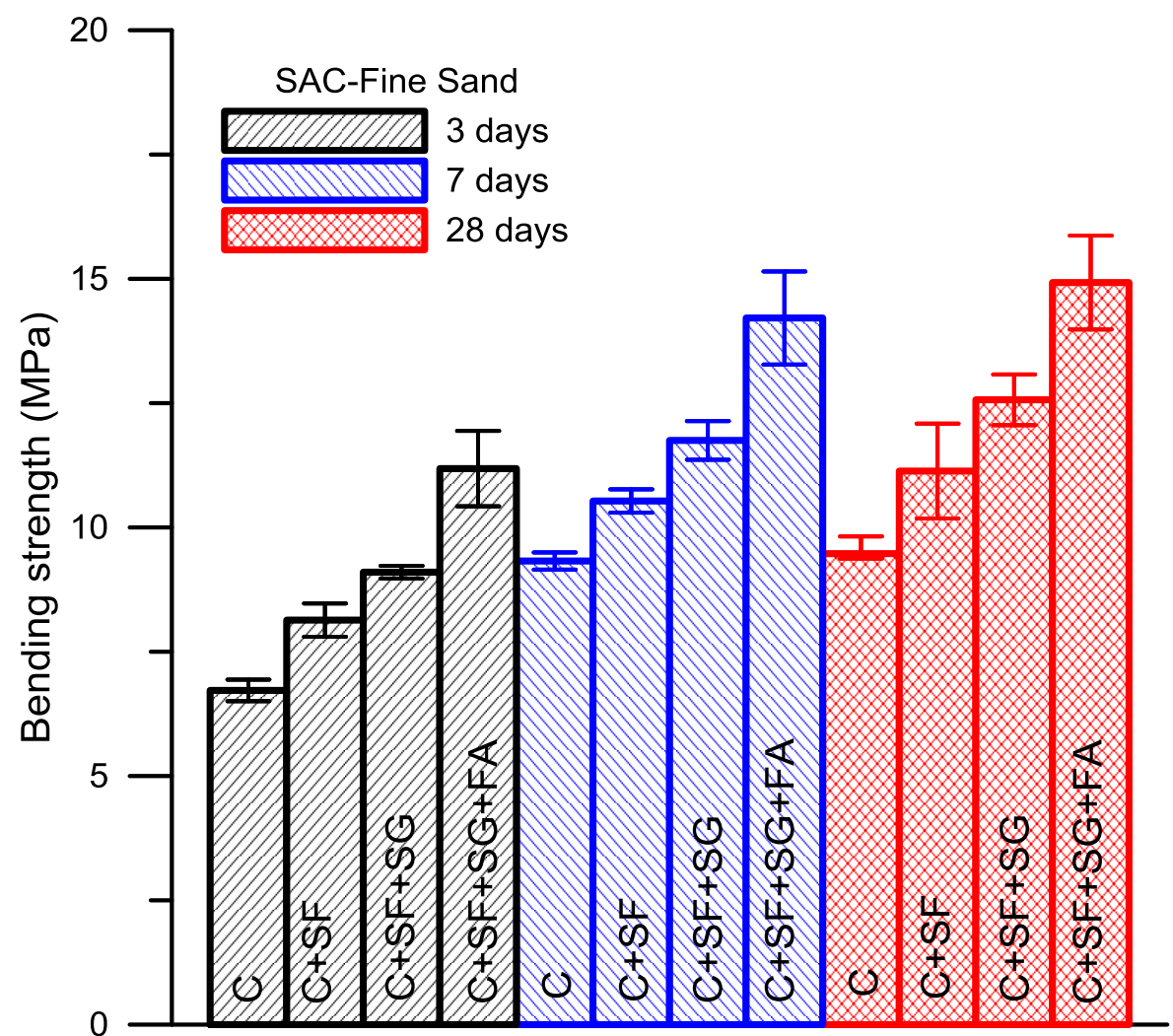

(b)

Fig.14 Effect of optimized SCM addition on compressive and bending strength of the SAC-fine sand mortar, (a) compressive strength, (b) bending strength 


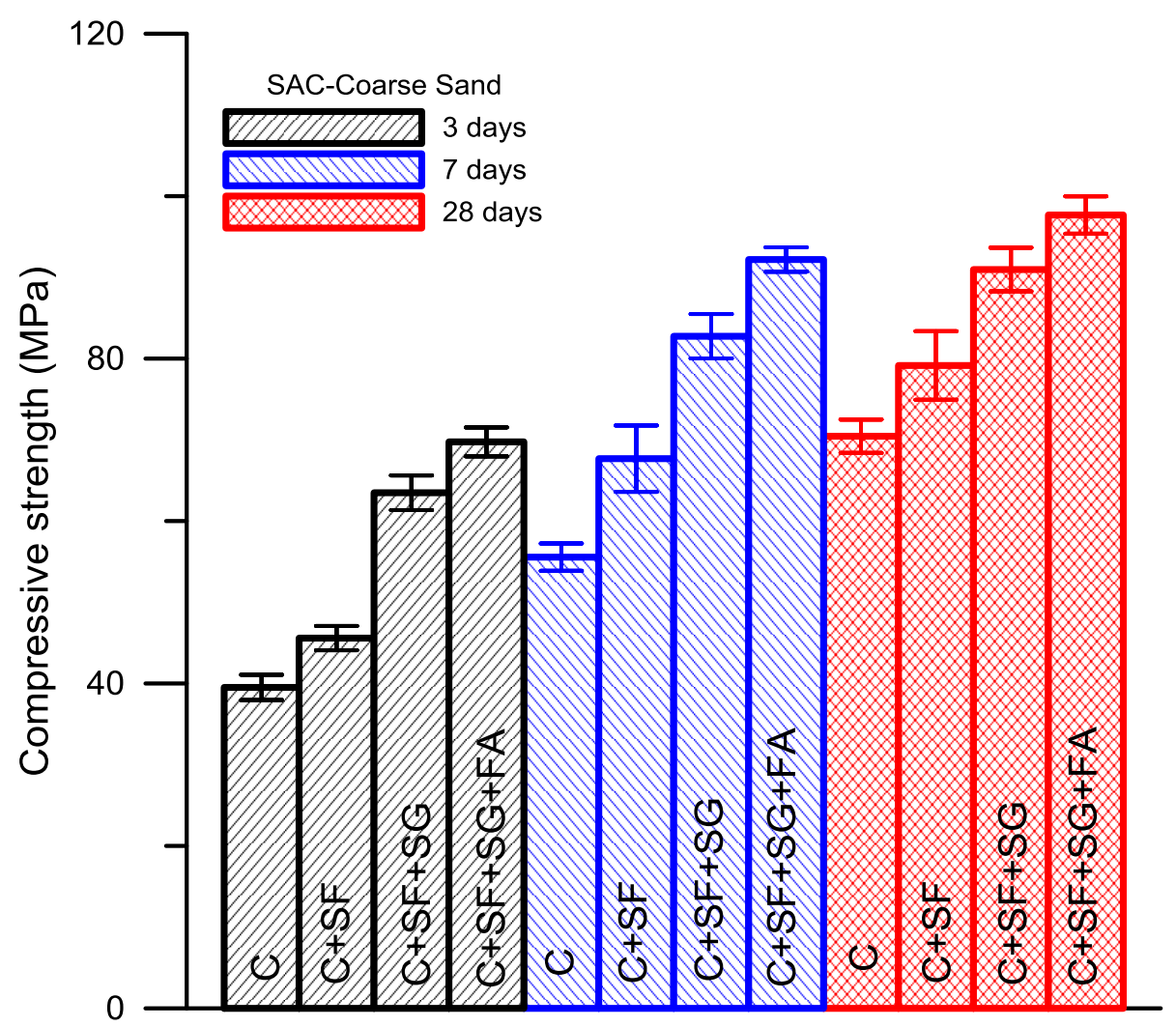

(a)

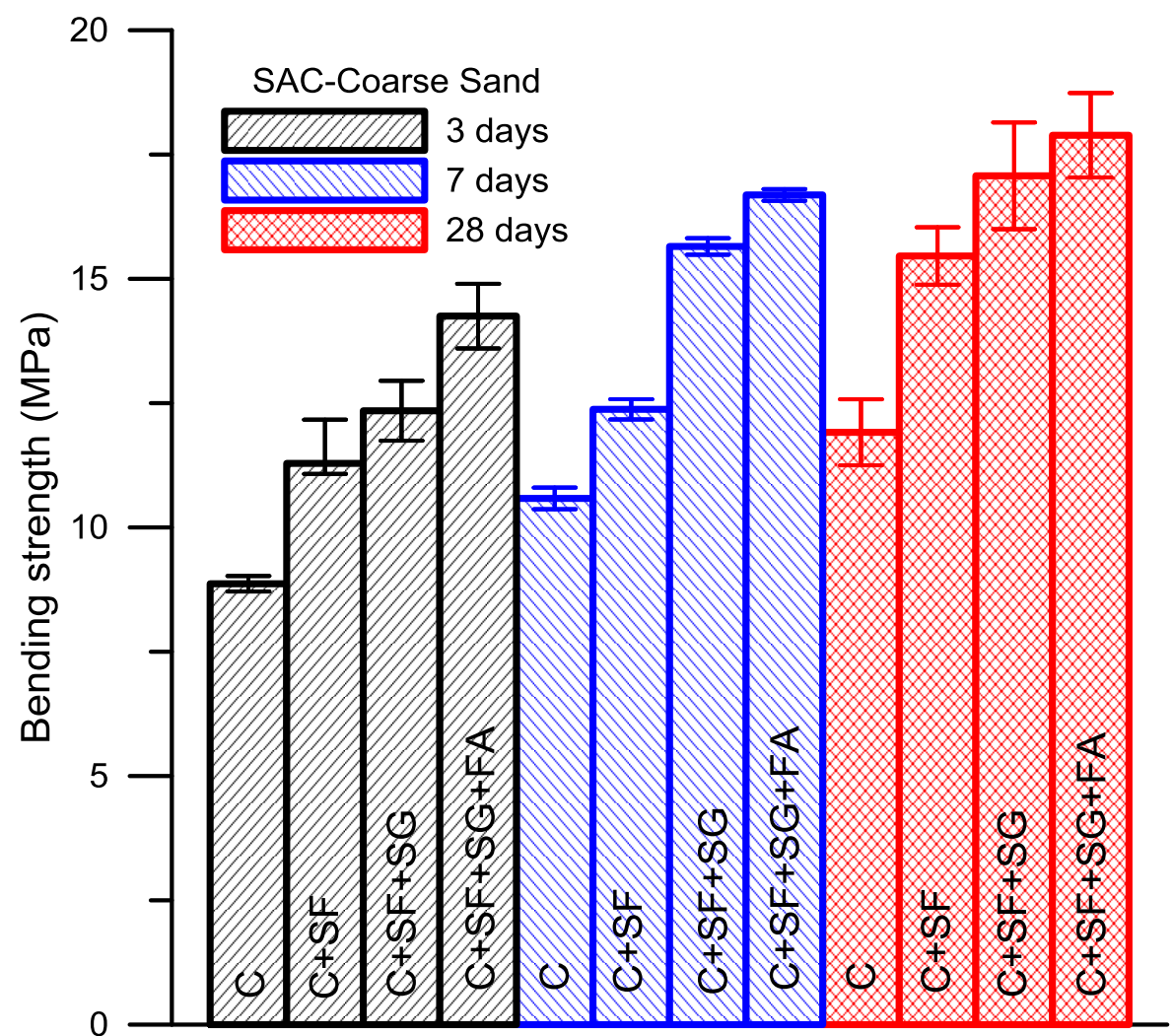

(b)

Fig.15 Effect of optimized SCM addition on compressive and bending strength of the SAC-coarse sand mortar, (a) compressive strength, (b) bending strength 


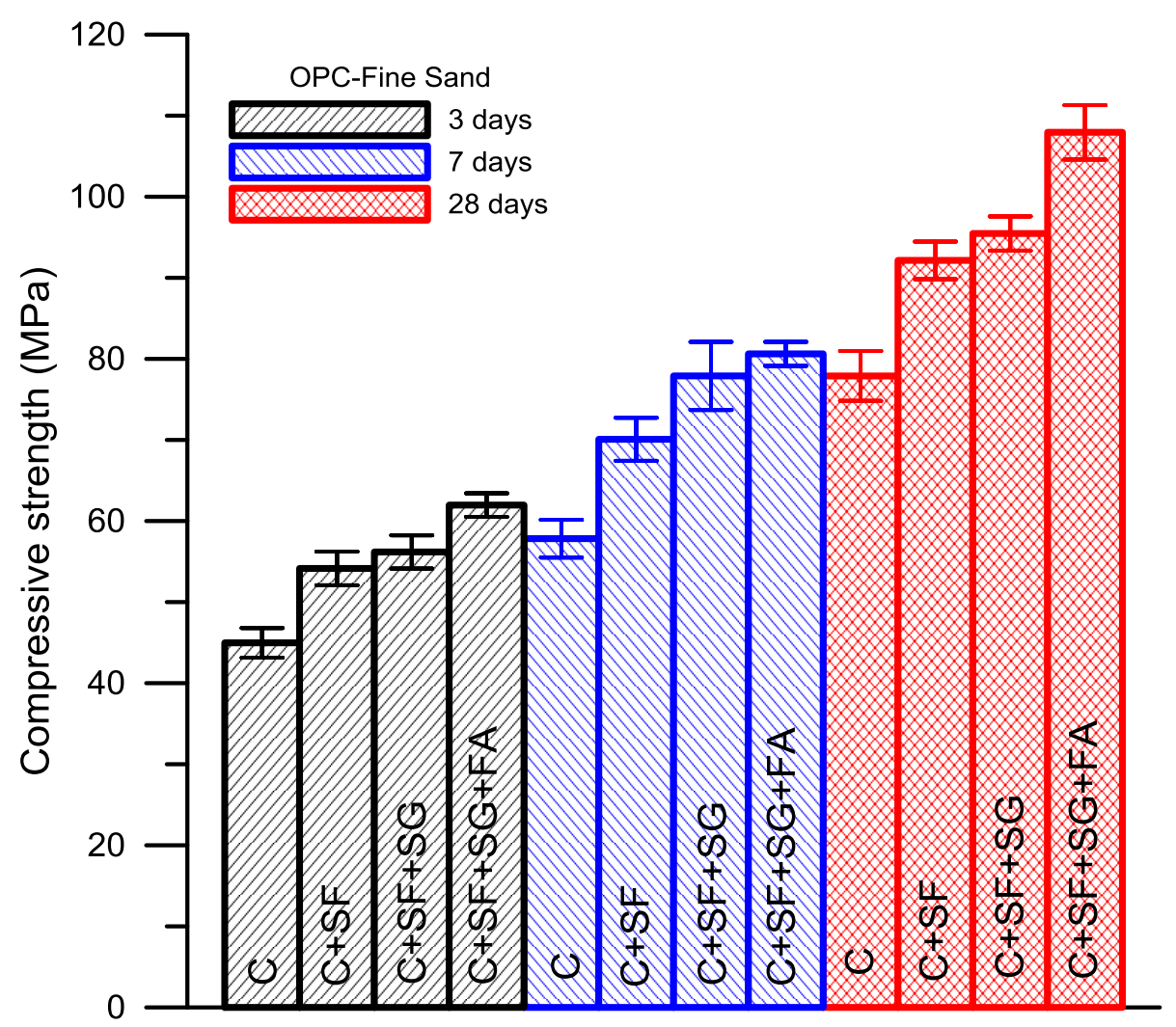

(a)

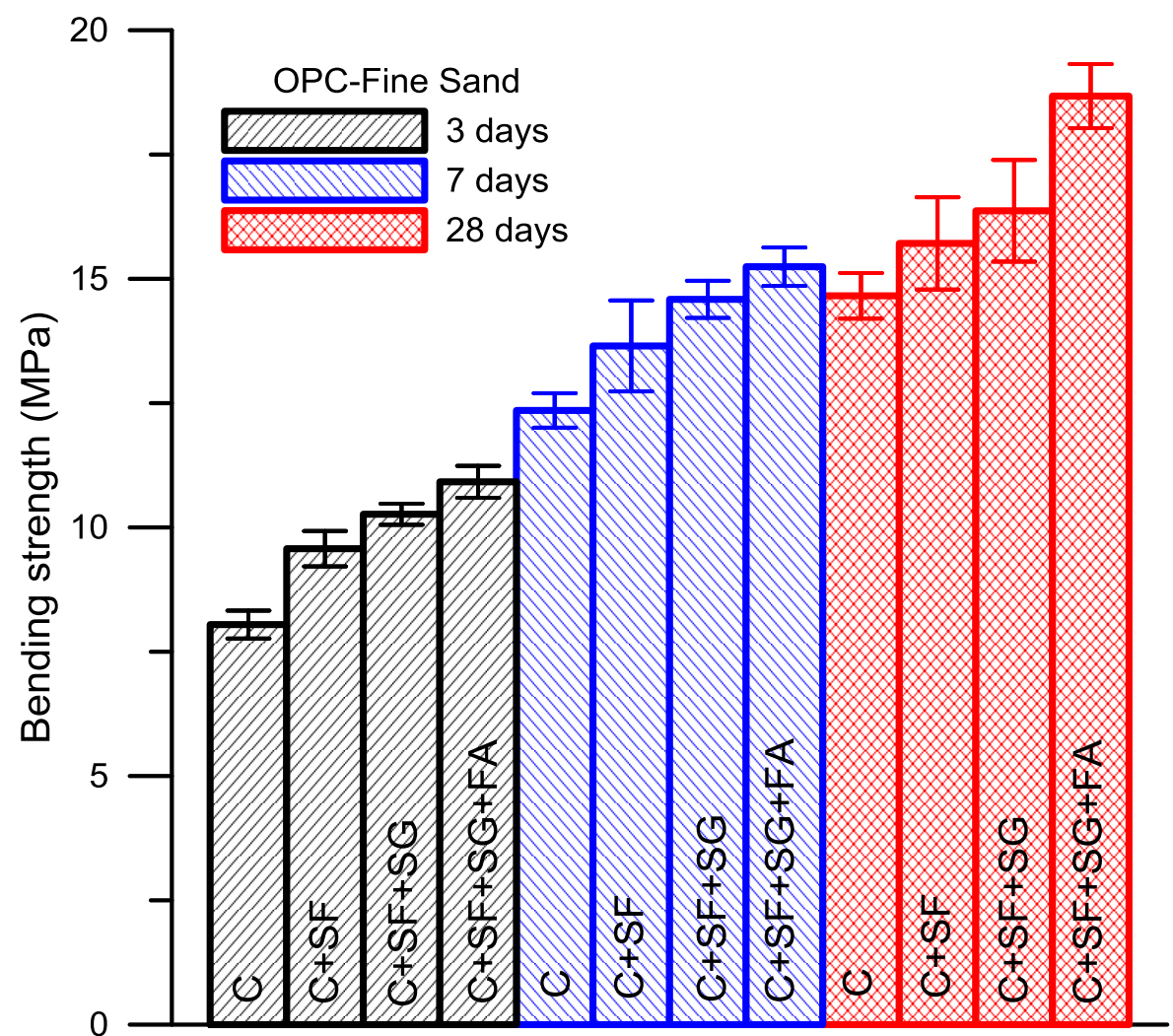

(b)

Fig.16 Effect of optimized SCM addition on compressive and bending strength of the OPC-fine sand mortar, (a) compressive strength, (b) bending strength 


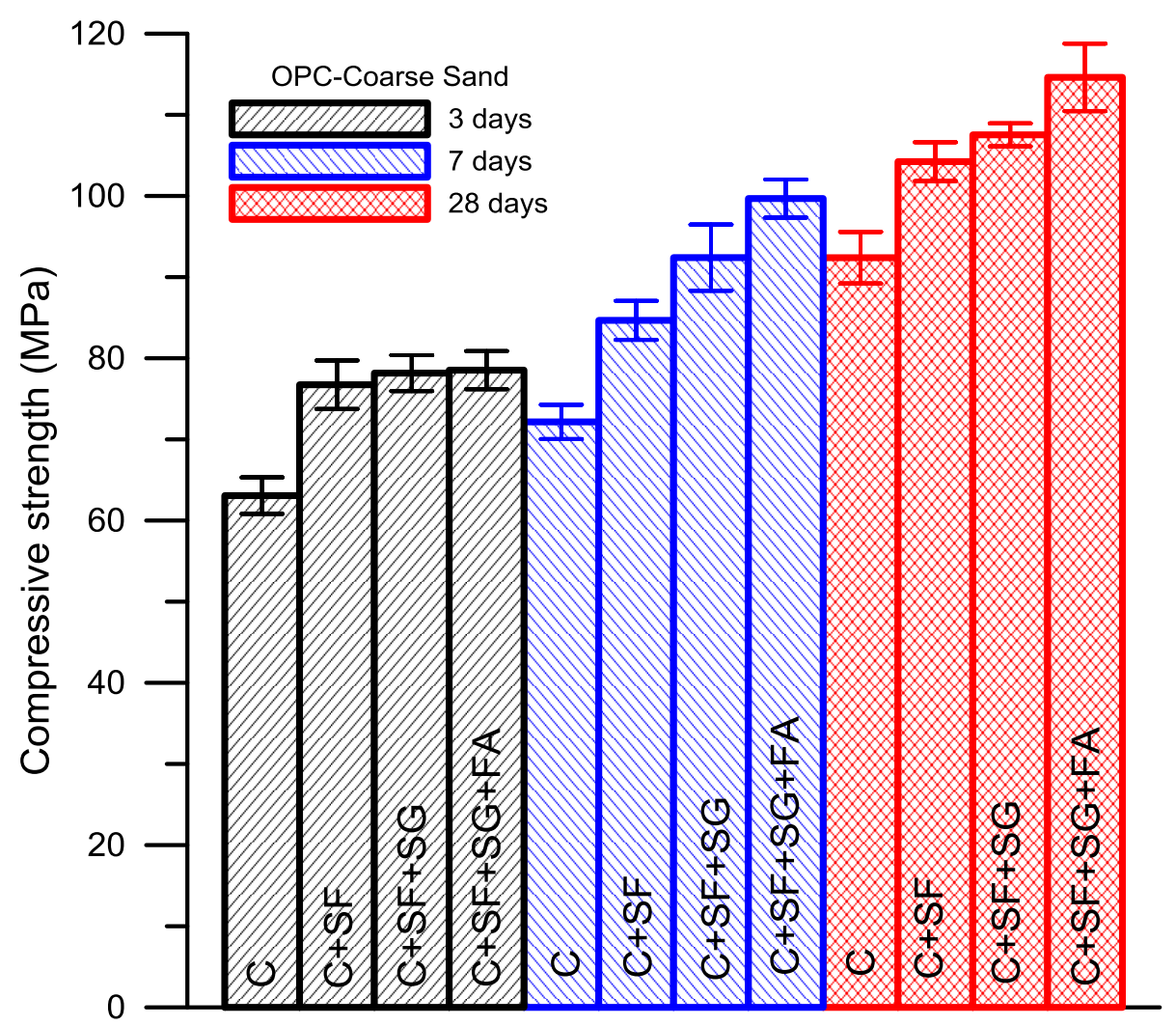

(a)

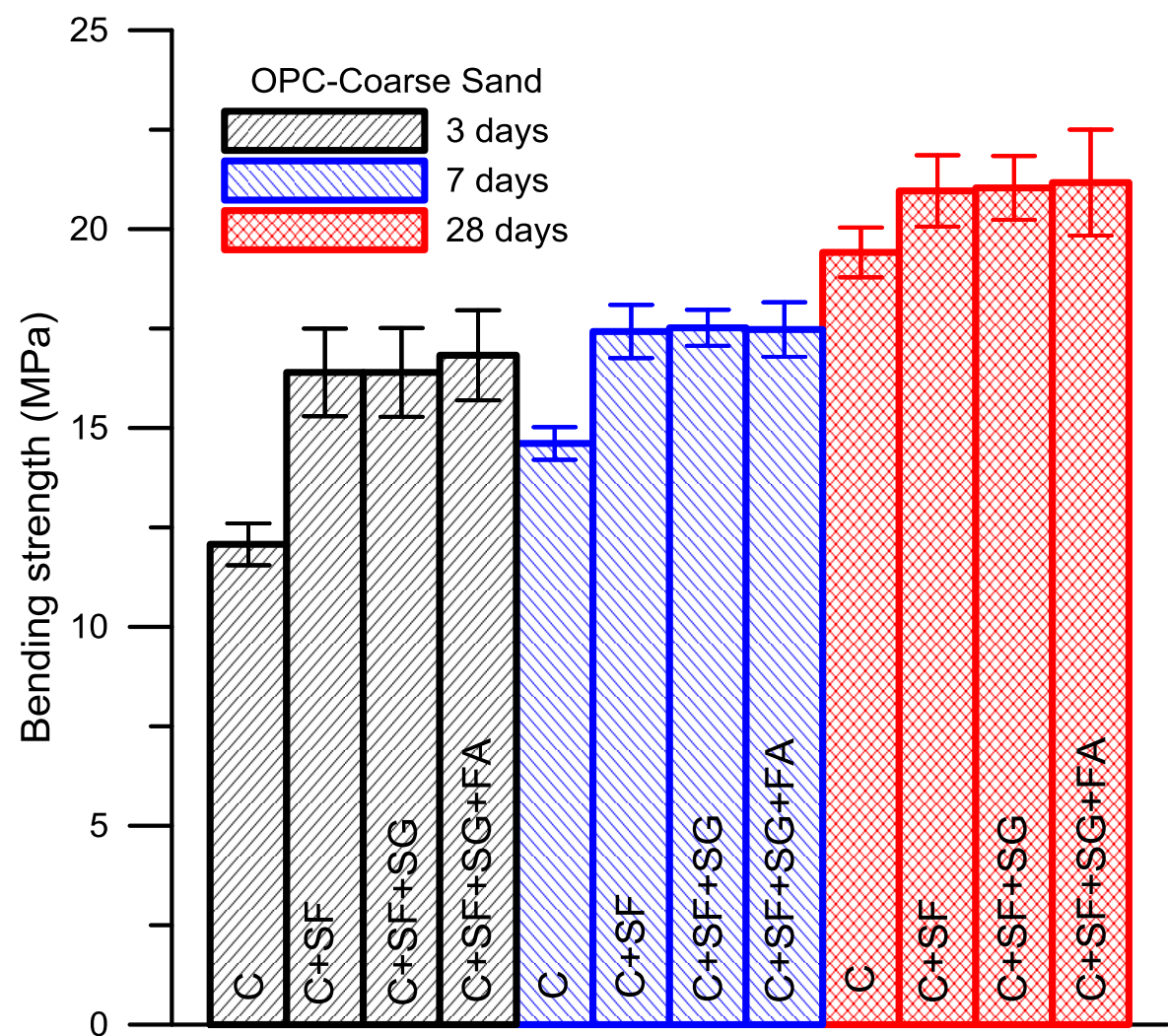

(b)

Fig.17 Effect of optimized SCM addition on compressive and bending strength of the OPC-coarse sand mortar, (a) compressive strength, (b) bending strength 


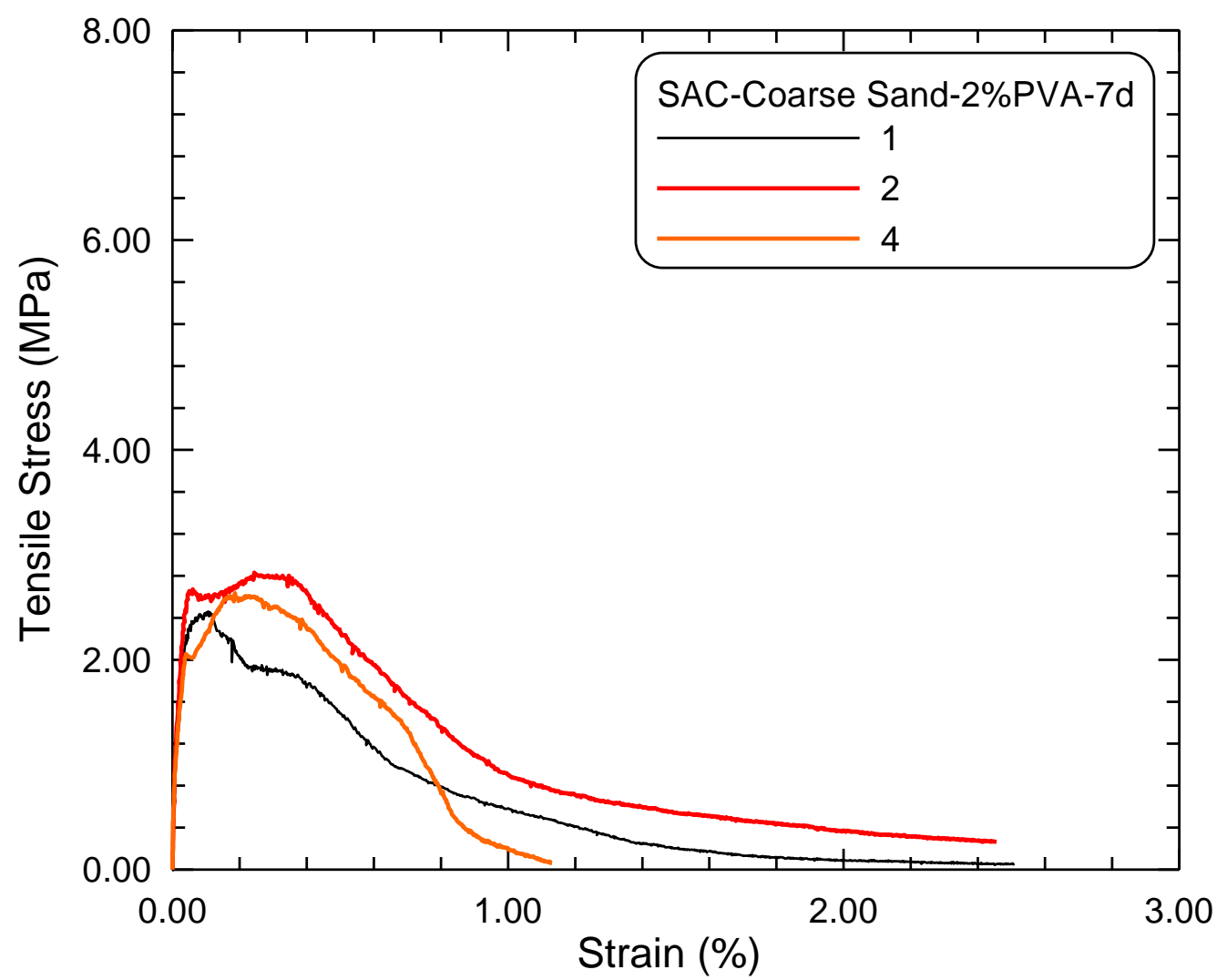

(a)

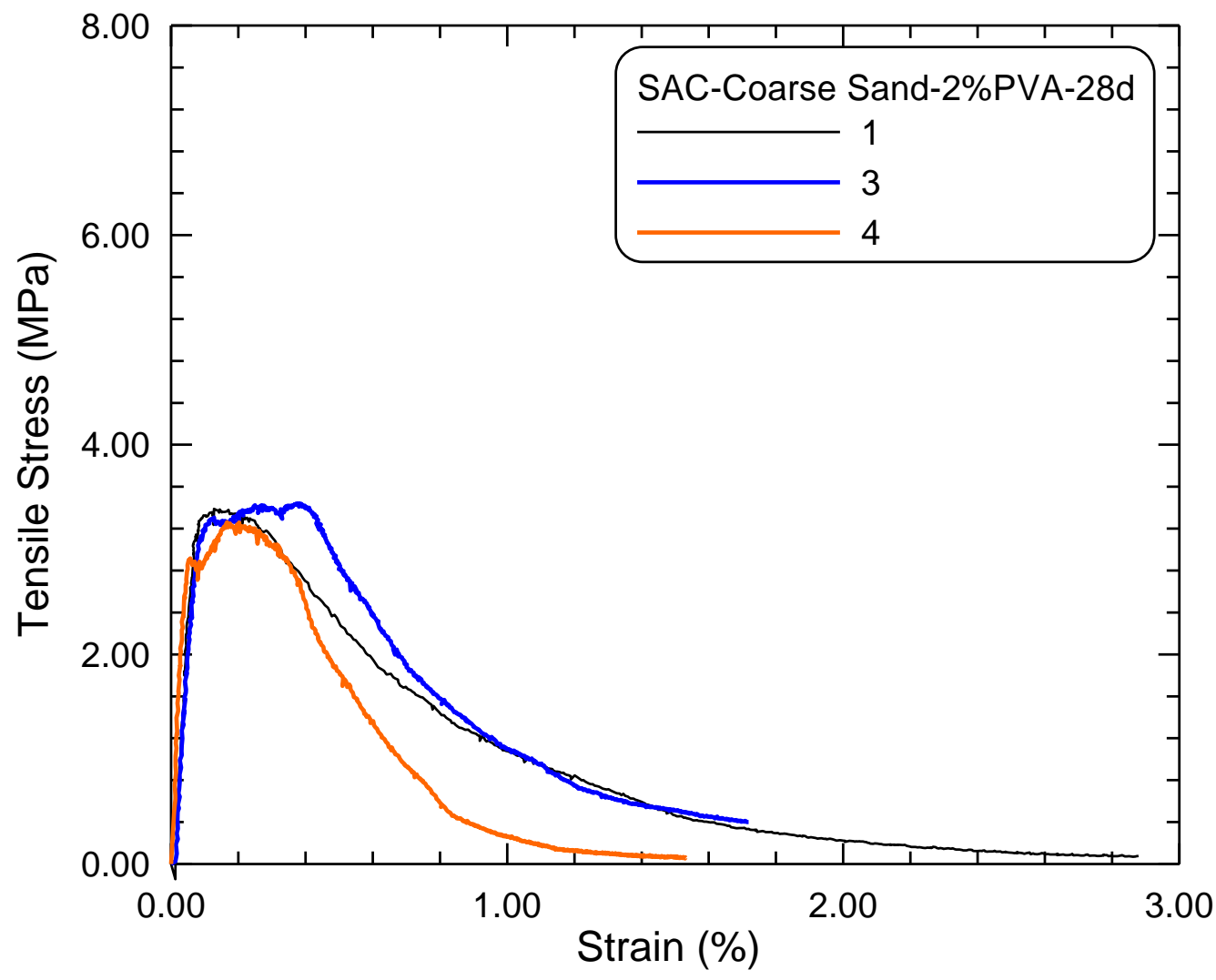

(b)

Fig. 18 Tensile stress-strain curves of SAC-coarse sand matrix reinforced with 2\% PVA fiber, (a) 7 days, (b) 28 days 


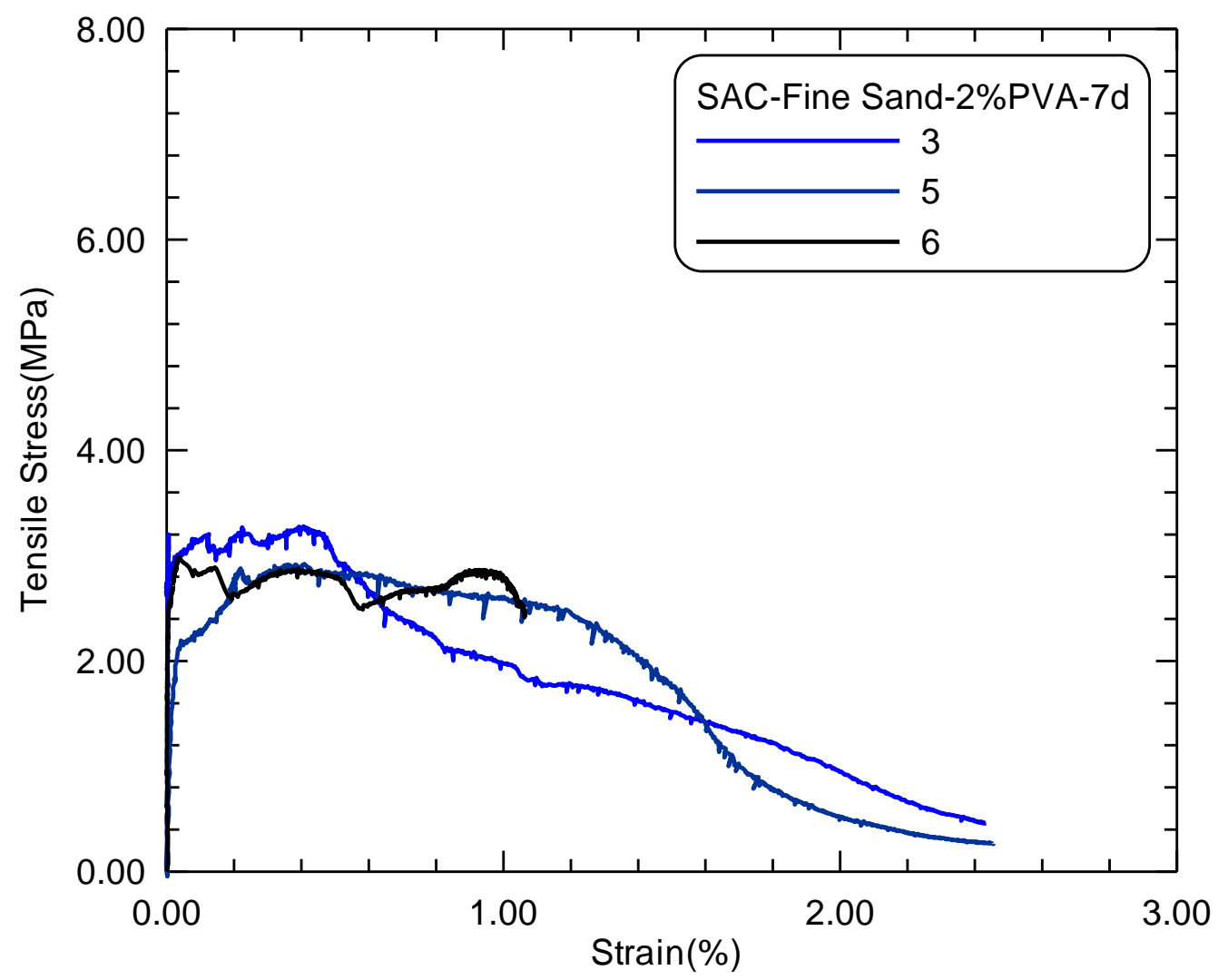

(a)

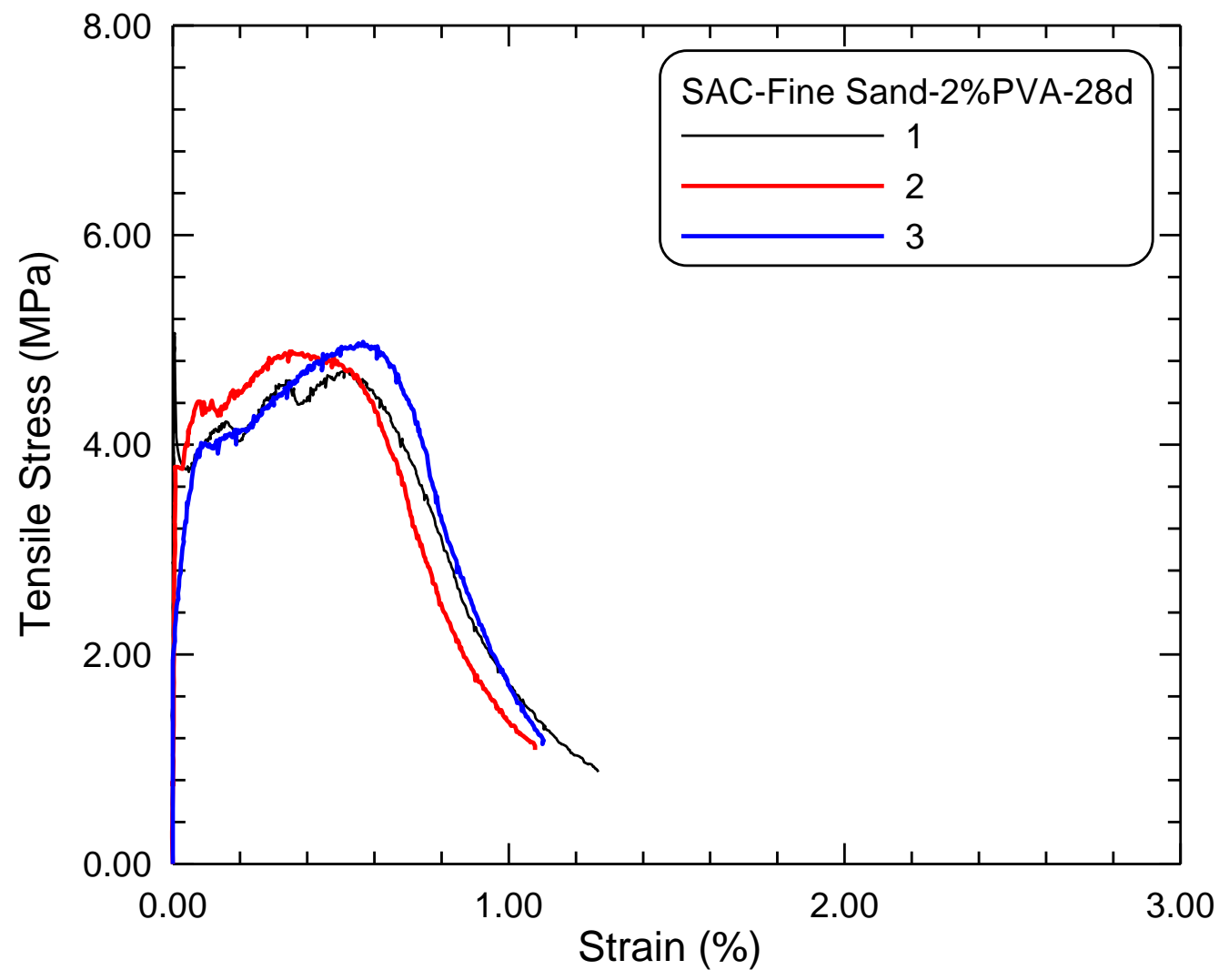

(b)

Fig.19 Tensile stress-strain curves of SAC-fine sand matrix reinforced with 2\% PVA fiber, (a) 7 days, (b) 28 days 


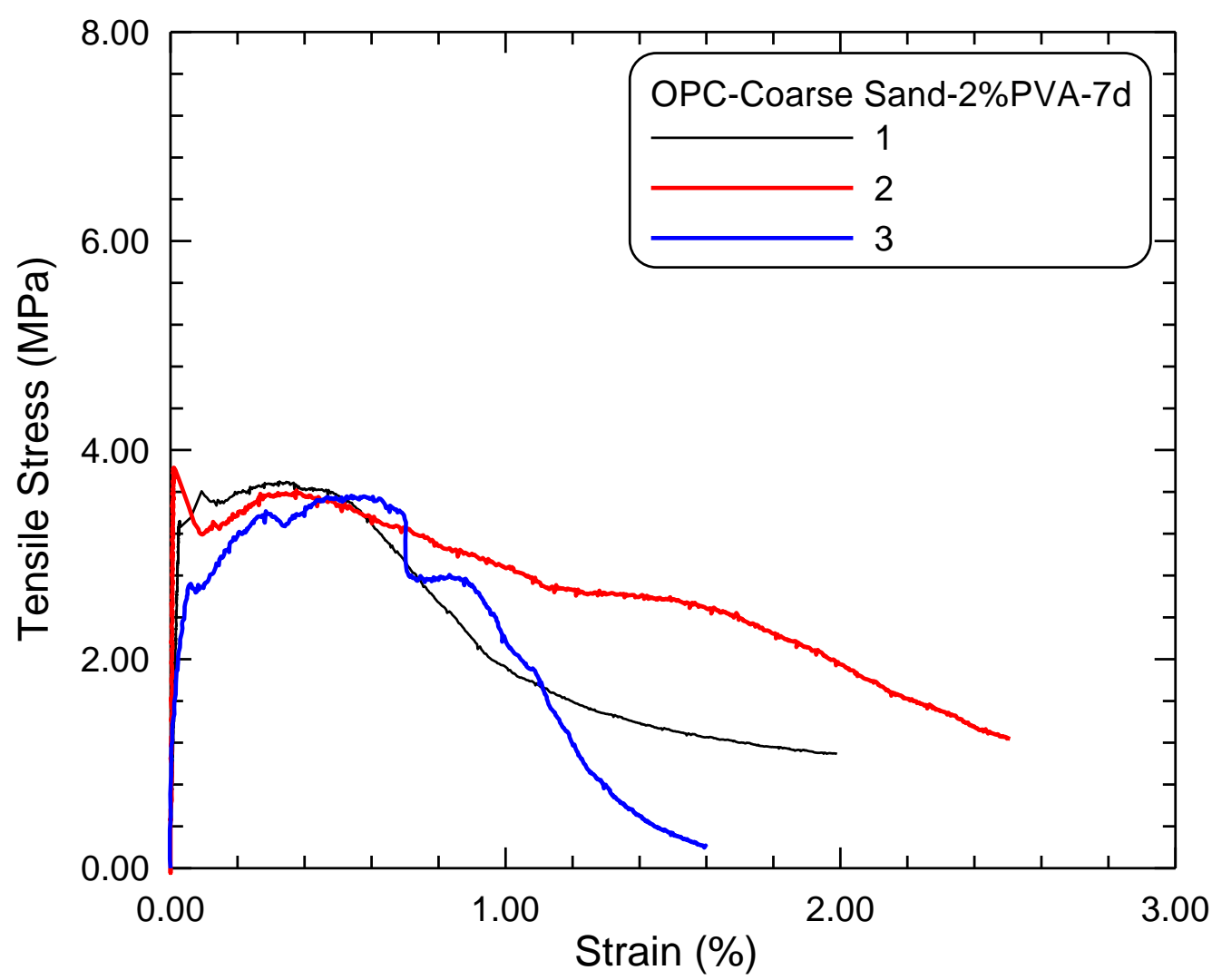

(a)

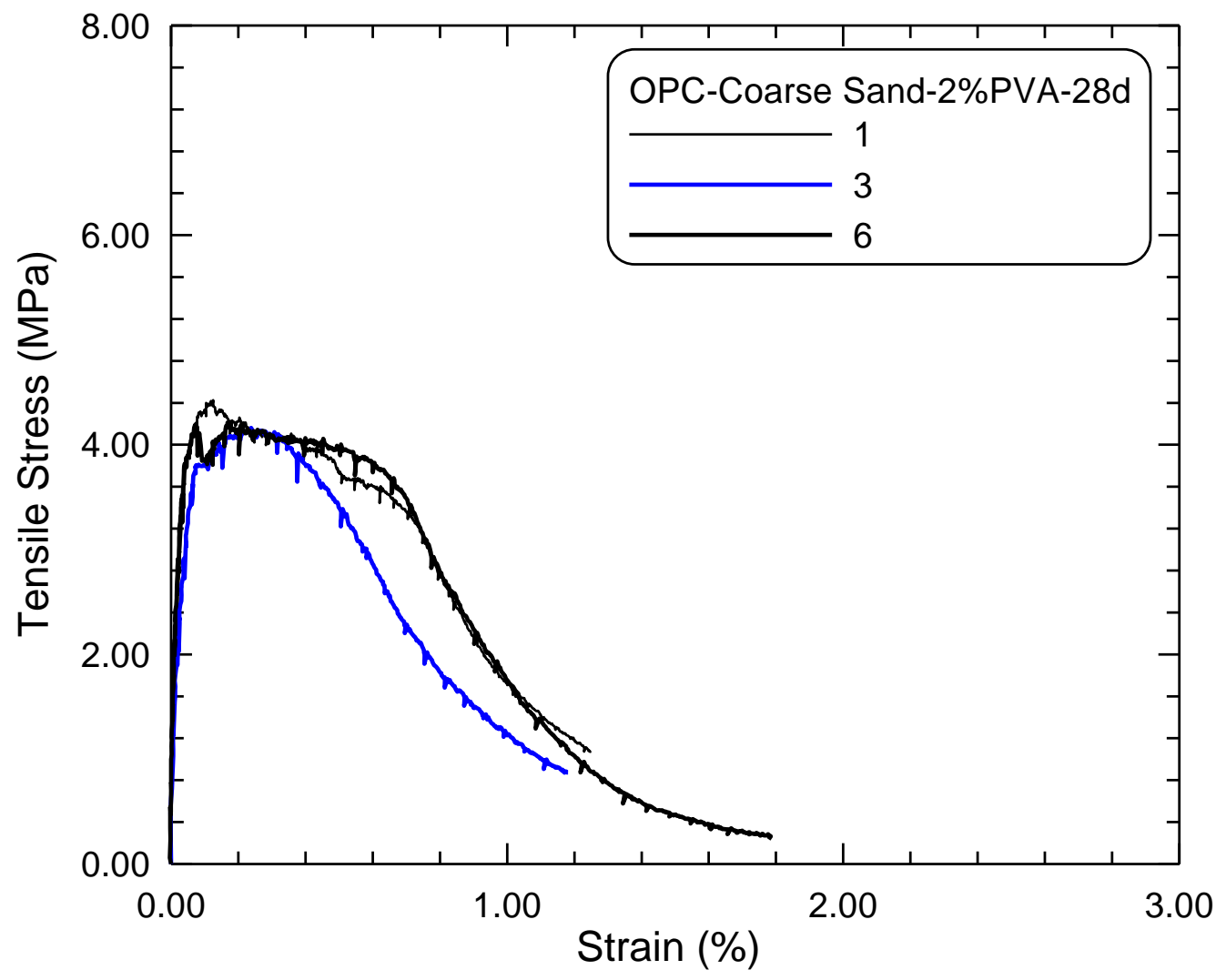

(b)

Fig.20 Tensile stress-strain curves of OPC-coarse sand matrix reinforced with $2 \%$ PVA fiber, (a) 7 days, (b) 28 days 


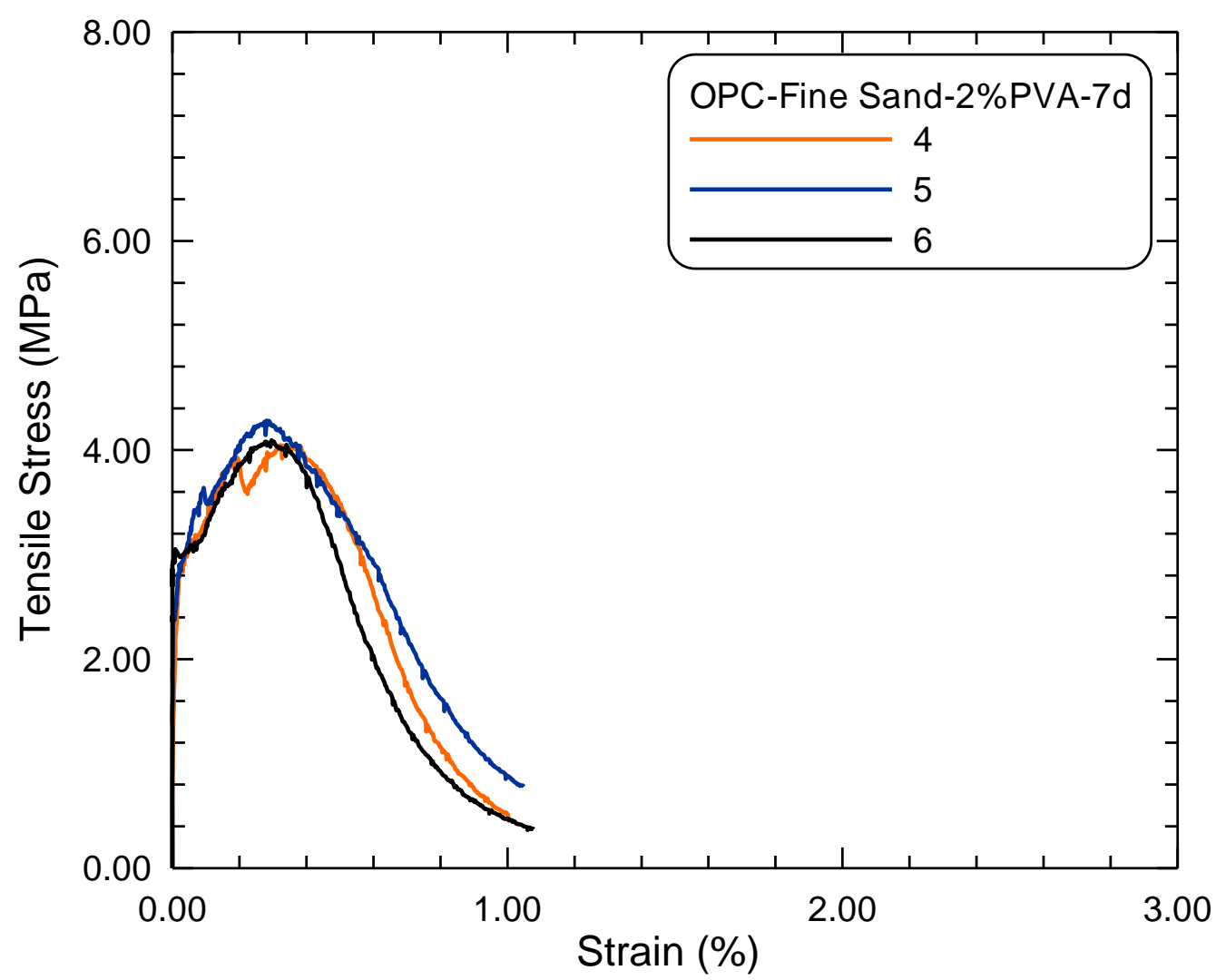

(a)

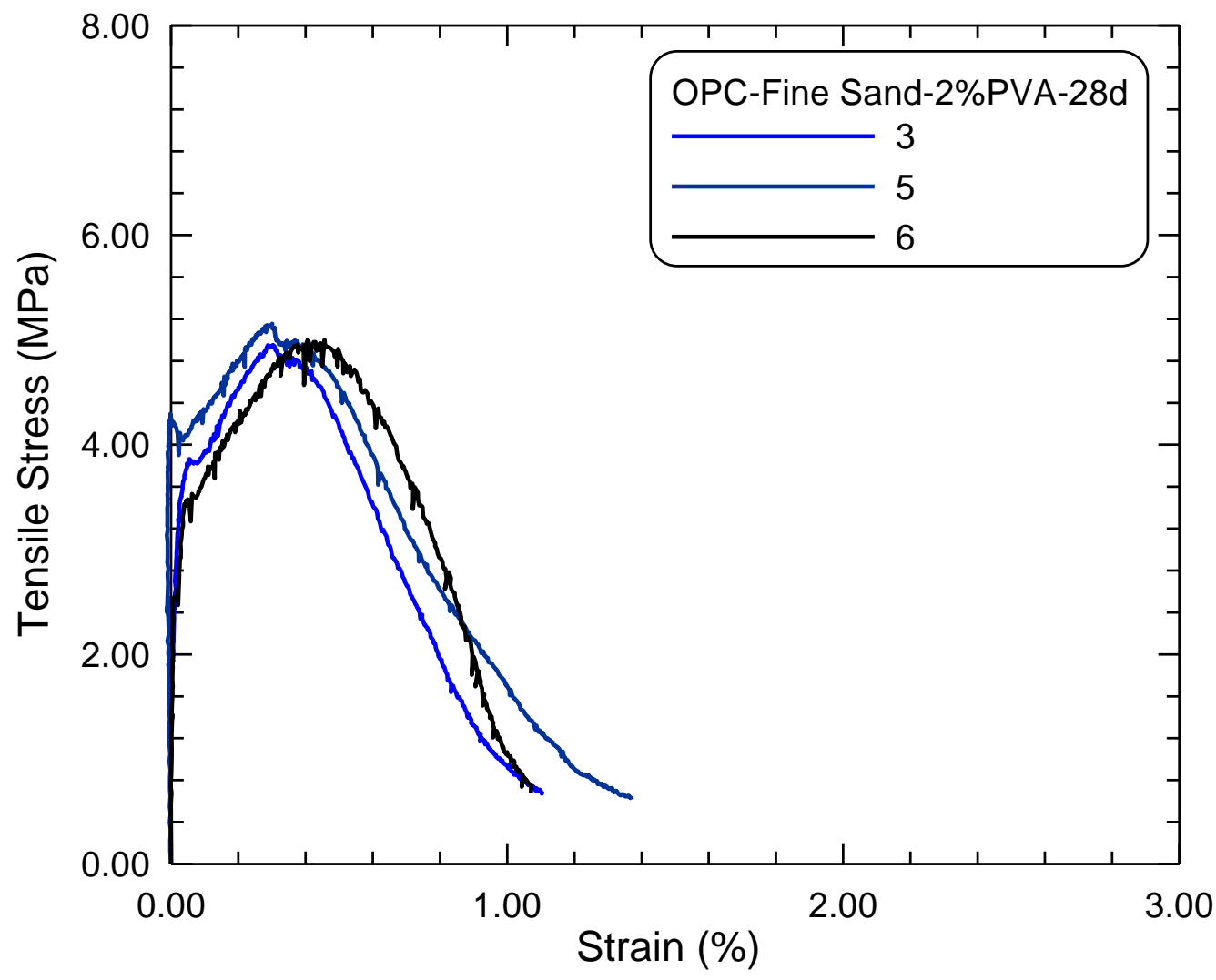

(b)

Fig.21 Tensile stress-strain curves of OPC-fine sand matrix reinforced with 2\% PVA fiber, (a) 7 days, (b) 28 days 


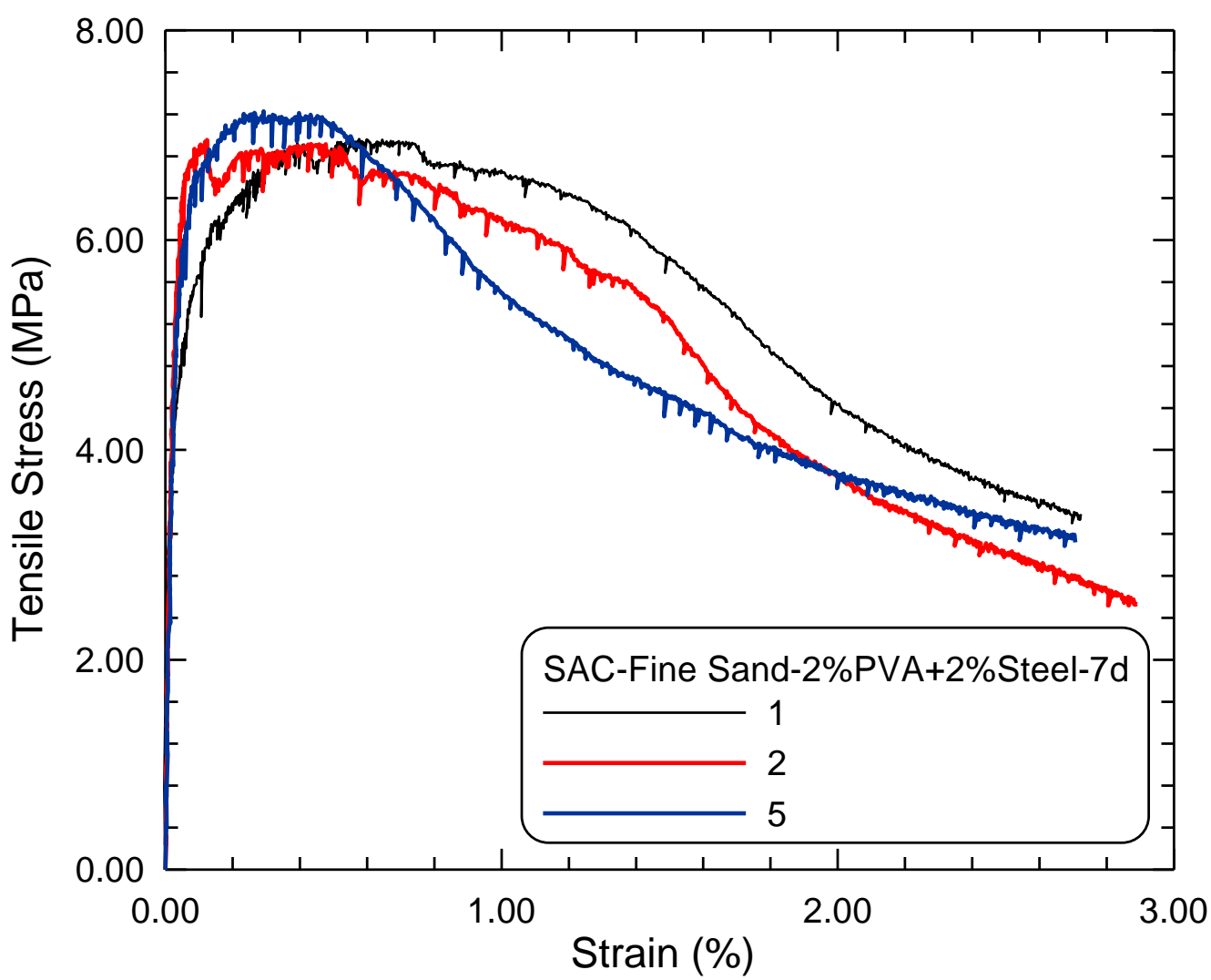

(a)

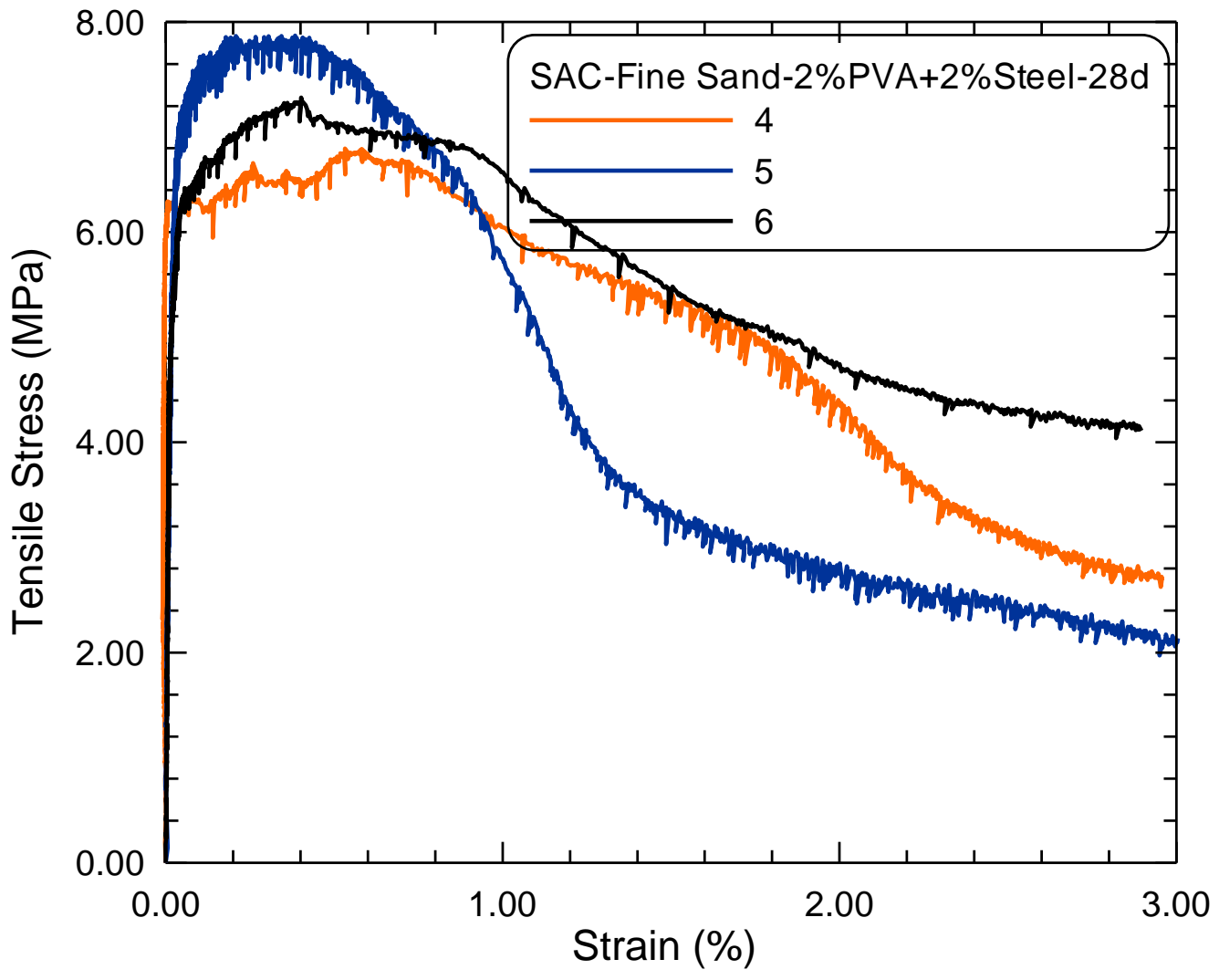

(b)

Fig.22Tensile stress-strain curves of SAC-fine sand matrix reinforced with 2\% PVA fiber and 2\% steel fiber, (a) 7 days, (b) 28 days 


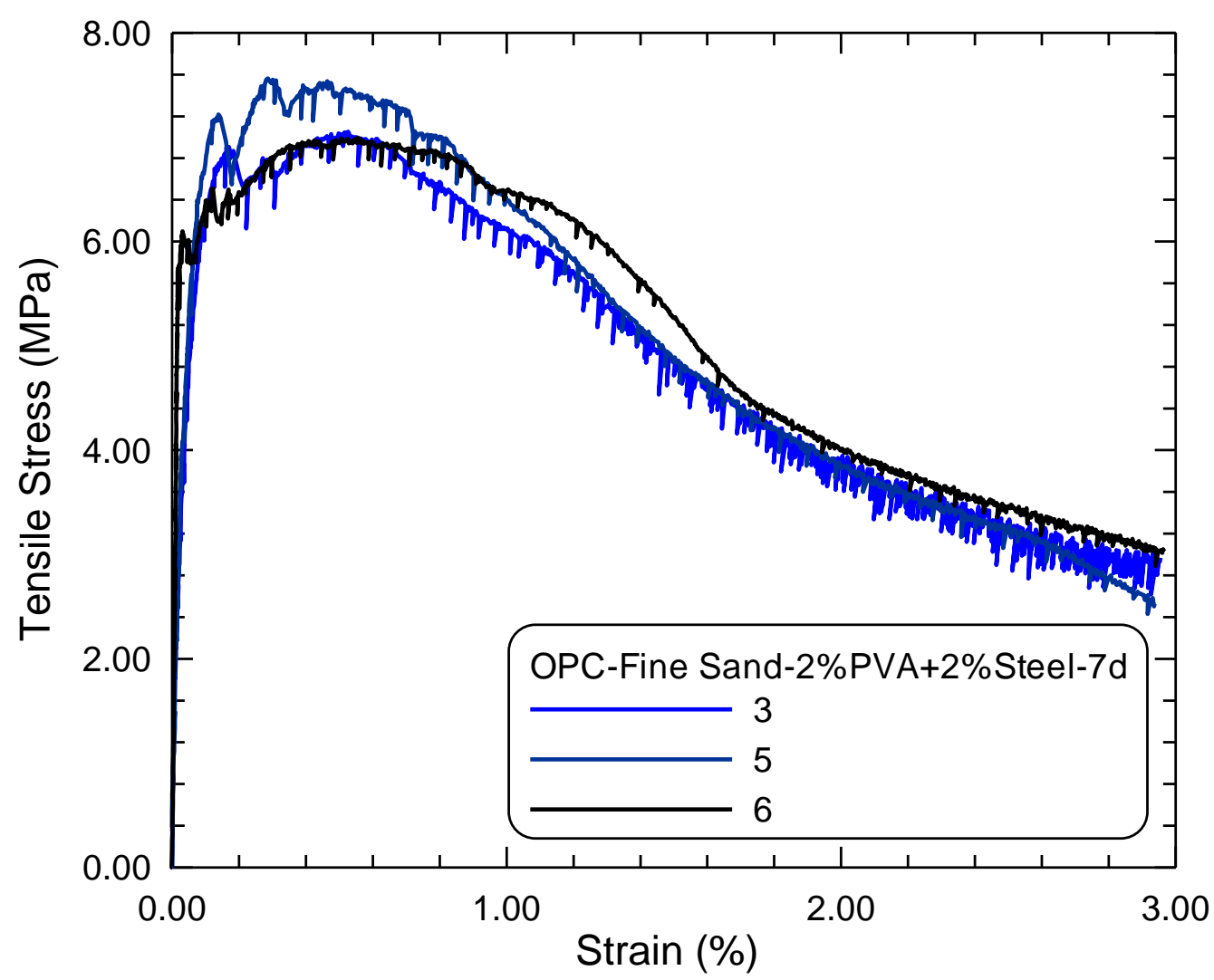

(a)

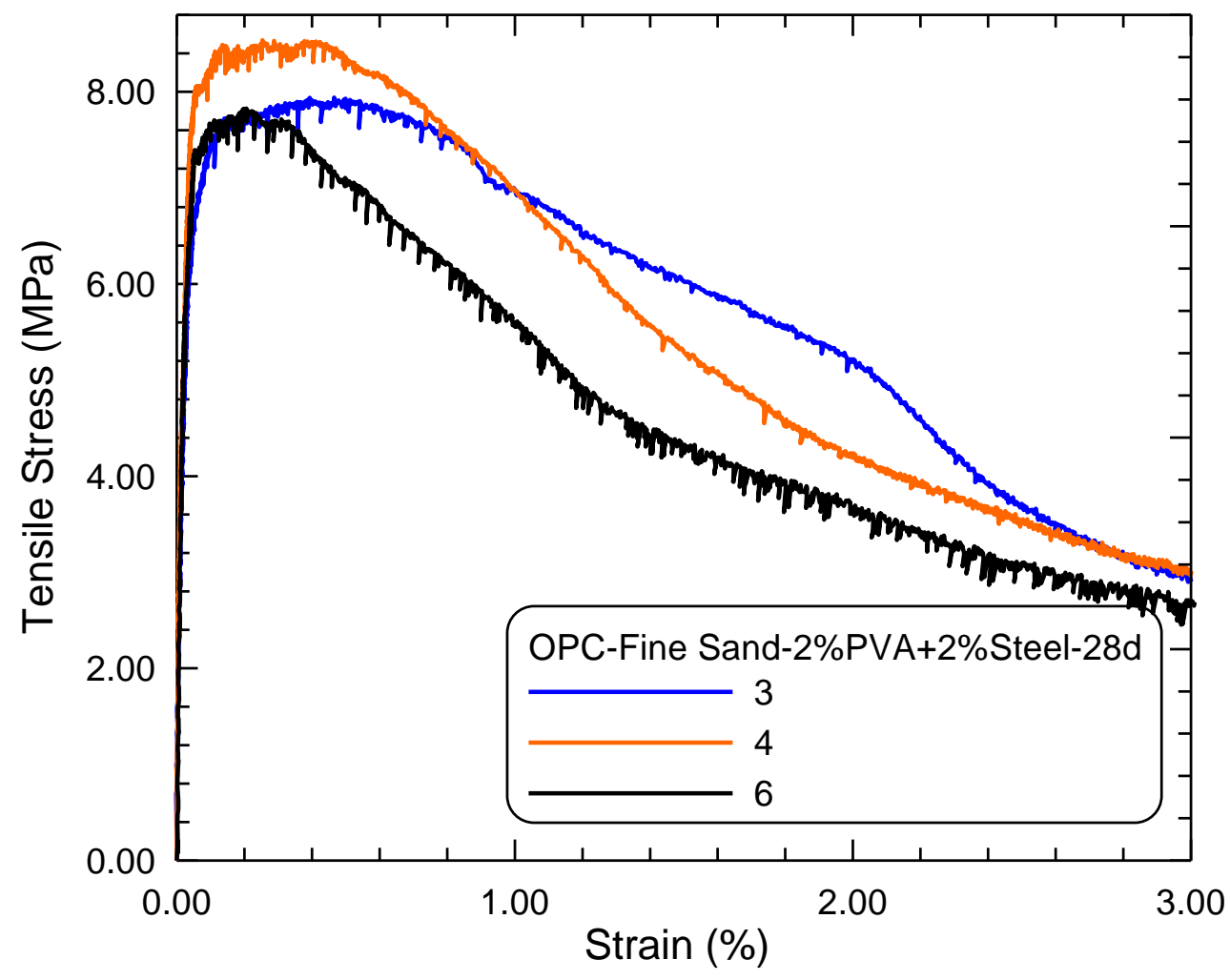

(b)

Fig.23 Tensile stress-strain curves of SAC-fine sand matrix reinforced with 2\% PVA fiber and 2\% steel fiber, (a) 7 days, (b) 28 days 